\title{
The role of intracoronary imaging in translational research
}

\author{
Nicholas J. Montarello ${ }^{1}$, Adam J. Nelson ${ }^{2,3}$, Johan Verjans ${ }^{1,2,4}$, Stephen J. Nicholls ${ }^{5}$, Peter J. Psaltis ${ }^{1,2,4}$ \\ ${ }^{1}$ Department of Cardiology, Central Adelaide Local Health Network, Adelaide, Australia; ${ }^{2}$ Adelaide Medical School, University of Adelaide, \\ Adelaide, Australia; ${ }^{3}$ Duke Clinical Research Institute, Durham, NC, USA; ${ }^{4}$ Vascular Research Centre, Heart and Vascular Program, Lifelong Health \\ Theme, South Australian Health and Medical Research Institute, Adelaide, Australia; ${ }^{5}$ Monash Cardiovascular Research Centre, Monash University, \\ Clayton, Australia \\ Contributions: (I) Conception and design: NJ Montarello, PJ Psaltis; (II) Administrative support: NJ Montarello, PJ Psaltis; (III) Provision of study \\ materials or patients: None; (IV) Collection and assembly of data: None; (V) Data analysis and interpretation: None; (VI) Manuscript writing: All \\ authors; (VII) Final approval of manuscript: All authors. \\ Correspondence to: Peter J. Psaltis, MBBS, PhD. Associate Professor, Deputy Leader, Vascular Research Centre, Heart and Vascular Program, Lifelong \\ Health Theme, South Australian Health and Medical Research Institute, PO Box 11060, Adelaide, SA 5001, Australia. Email: peter.psaltis@sahmri.com.
}

\begin{abstract}
Atherosclerotic cardiovascular disease is a key public health concern worldwide and leading cause of morbidity, mortality and health economic costs. Understanding atherosclerotic plaque microstructure in relation to molecular mechanisms that underpin its initiation and progression is needed to provide the best chance of combating this disease. Evolving vessel wall-based, endovascular coronary imaging modalities, including intravascular ultrasound (IVUS), optical coherence tomography (OCT) and near-infrared spectroscopy (NIRS), used in isolation or as hybrid modalities, have been advanced to allow comprehensive visualization of the pathological substrate of coronary atherosclerosis and accurately measure temporal changes in both the vessel wall and plaque characteristics. This has helped further our appreciation of the natural history of coronary artery disease (CAD) and the risk for major adverse cardiovascular events (MACE), evaluate the responsiveness to conventional and experimental therapeutic interventions, and assist in guiding percutaneous coronary intervention (PCI). Here we review the use of different imaging modalities for these purposes and the lessons they have provided thus far.
\end{abstract}

Keywords: Coronary artery disease (CAD); intracoronary imaging; intravascular ultrasound (IVUS); near-infrared spectroscopy (NIRS); optical coherence tomography (OCT); plaque imaging

Submitted Jan 02, 2020. Accepted for publication Apr 20, 2020.

doi: $10.21037 / \mathrm{cdt}-20-1$

View this article at: http://dx.doi.org/10.21037/cdt-20-1

\section{Introduction}

Translational research is fundamentally the multidirectional integration of basic, patient-oriented and population-based research, with the long-term aim of improving the health of the public (1). Appearing in peer reviewed literature as early as 1993 , what best defines translational research has been less clear than that of basic and clinical research. However, at its core, translational research aims to inform the understanding and treatment of clinical disease through mechanistic insight, essentially moving observations from the researcher's bench to the patient's bedside and the wider community (2).
There have been few investigative tools in cardiovascular research that have provided as transformative insights as intravascular imaging has for coronary artery disease (CAD). The ability to directly visualize atherosclerosis and its temporal course has bridged the critical gap between cellular models of atherogenesis and the anatomical expression of disease post-mortem. Initially utilized in pre-clinical models of disease, endovascular imaging has moved from human imaging biomarker to clinical tool in the contemporary treatment of CAD. More than 30 years of technological advancement has refined intravascular ultrasound (IVUS) and more recently spawned the development of other modalities, such as optical coherence tomography (OCT) 
and near-infrared spectroscopy (NIRS).

While traditional invasive coronary angiography (CAG) remains the gold standard for the determination of obstructive, luminal stenosis in clinical practice (3), its inability to image the vessel wall and its quantitative imprecision caused by inherent variations in equipment and inter-observer differences, have limited its capacity for serial evaluation of plaque burden (PB) and response to therapy (4). In contrast, the endovascular imaging modalities listed above, some of which are now integrated, provide a means of measuring temporal changes within the vessel wall with high fidelity. This review describes the currently available intracoronary imaging modalities and summarizes the evidence that their use has generated in: (I) determining the natural history of $\mathrm{CAD}$ and its associated risk of major adverse cardiovascular events (MACE) (5); (II) evaluating the responsiveness of CAD to established and experimental therapeutic interventions (6); and (III) guiding percutaneous coronary intervention (PCI).

\section{Invasive imaging modalities for serial CAD assessment}

\section{IVUS}

Basic or conventional grayscale IVUS involves the positioning of a catheter containing a high-frequency ultrasound transducer within the lumen of coronary arteries adjacent to the vessel wall. This permits cross-sectional imaging and provides an extensive view of the distribution and nature of $\mathrm{PB}$ within the vessel wall (7) (Figure 1).

Virtual histology IVUS (VH-IVUS) utilizes advanced radiofrequency analysis of reflected ultrasound signals. A reconstructed color-coded tissue map of plaque composition is superimposed onto conventional cross-sectional grayscale IVUS images, allowing fibrous, fibrofatty, necrotic core and dense calcific material to be distinguished (8).

\section{$O C T$}

OCT employs near-infrared light, typically of a wavelength of approximately $1,300 \mathrm{~nm}$, to create detailed images of plaque atheroma in the coronary arteries (Figure 1). Its particular advantage is its high spatial resolution (approximately ten-times higher than that of IVUS) with an axial resolution of up to $10 \mu \mathrm{m}$ and lateral resolution of up to $20 \mu \mathrm{m}(9,10)$. This enables qualitative and quantitative analysis of the atheroma below the intimal endothelial surface, providing the ability to discriminate between fibrous, lipid-rich and calcified plaques $(9,11,12)$, quantitate lipid content and macrophage burden $(11,13)$ and accurately measure fibrous cap thickness (12). However, the benefit of high imaging resolution is offset by OCT's poor tissue penetration, compromising its ability to image the full thickness and deeper layers of atherosclerotic plaques.

\section{NIRS}

NIRS is based on the absorbance of light by organic molecules and determines the characteristics of the chemical components of tissue samples. In its most widely used form it is used for lipid detection (14). Spectroscopic information is transformed into a probability of lipid core that is mapped to a red-to-yellow color scale, with low probability of lipid shown as red and high probability of lipid shown as yellow. Yellow pixels within the analyzed segment are then divided by all viable pixels to generate the lipid-core burden index (LCBI) (15) (Figure 1).

\section{Near-infrared fluorescence (NIRF) and near-infrared autofluorescence (NIRAF)}

NIRF has been evaluated in pre-clinical models of atherosclerosis because of its capacity to detect the biology of the plaque, such as inflammatory protease activity, macrophage composition, chemokines, presence of fibrin, cellular apoptosis and neo-angiogenesis. This technology uses near-infrared laser light to excite and detect fluorescent molecular structures, or fluorophores, which are cable of binding to various molecular targets. Intravascular NIRFsensing catheters, integrated with OCT systems, have been used to in hybrid catheters to detect NIRF-emitting agents in context of structural images obtained with OCT. Early in its use NIRF has been coupled with indocyanine green (ICG), an amphiphilic near-infrared fluorophore, to identify plaque features of instability in areas of endothelial disruption, including inflammation, angiogenesis and lipidrich plaque (LRP) $(16,17)$. The development of more specific NIRF-emitting probes which target macrophage mannose receptors have shown potential to extend this panel (18). The first hybrid OCT-fluorescence imaging has been performed in patients using autofluorescence, without the need to administer an exogenous contrast agent (19). Although it was postulated that autofluorescence is associated with products of plaque hemorrhage, further studies are needed to demonstrate the clinical relevance of 

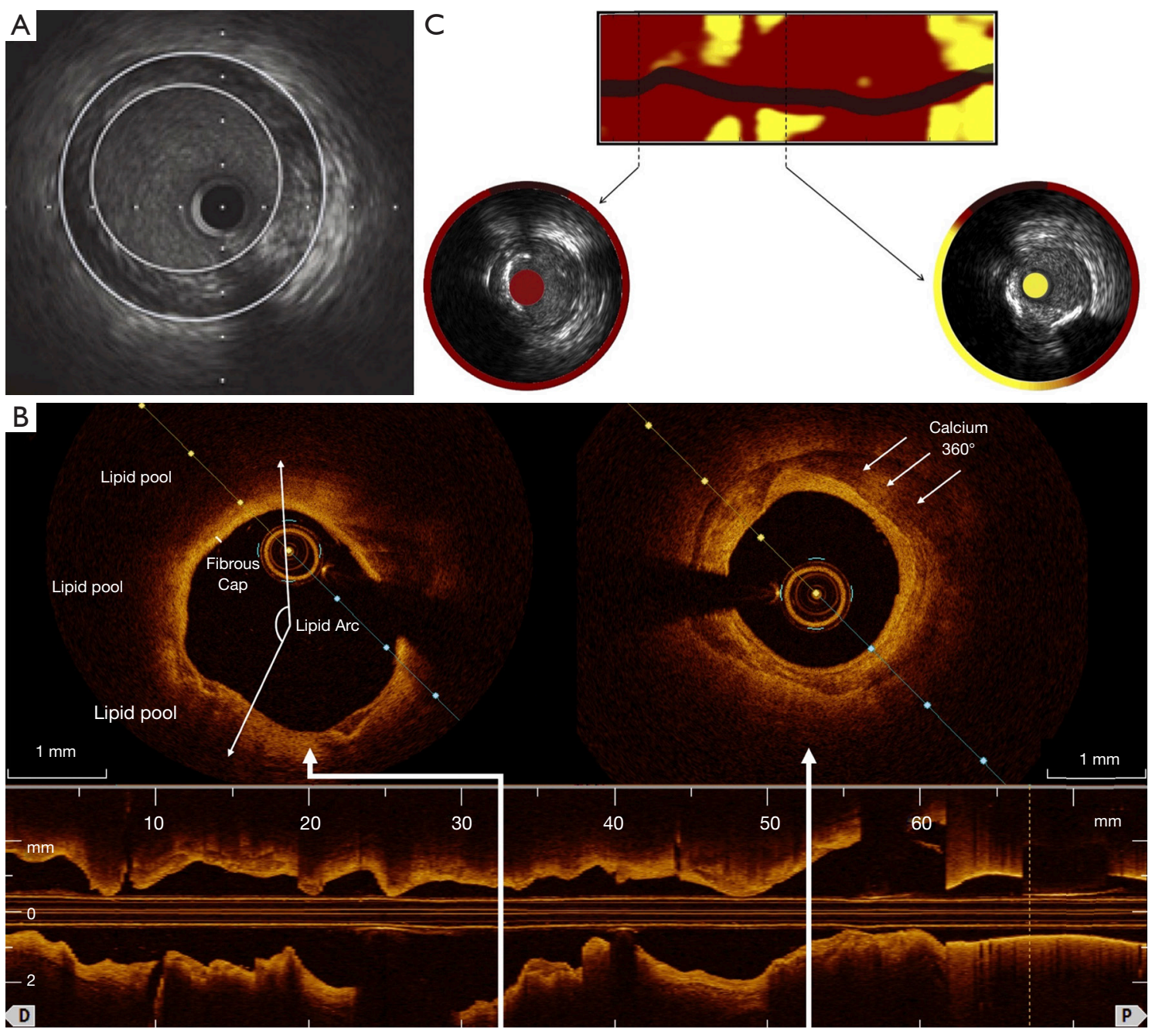

Figure 1 Different intracoronary plaque imaging modalities. (A) Cross-sectional view of gray-scale IVUS imaging demonstrating coronary PB; (B) coronary atherosclerotic plaque imaging with OCT; (C) coronary artery imaging with a cross-sectional view of IVUS highlighting plaque and NIRS demonstrating lipid (yellow) content. IVUS, intravascular ultrasound; PB, plaque burden; OCT, optical coherence tomography; NIRS, near-infrared spectroscopy.

autofluorescence imaging and its mechanism (20).

\section{Role of intracoronary imaging in translational research}

Translational research, utilizing intracoronary imaging, has focused on several principle areas: (I) assessing the natural history of stable and unstable (vulnerable) atherosclerotic plaque; (II) therapeutic modulation of atherosclerosis; and (III) guiding the deployment of stents and scaffolds during PCI and monitoring their progress over time.

\section{Histological basis of atherosclerosis}

Atherosclerotic cardiovascular disease is the principle contributor to mortality worldwide $(21,22)$. Despite significant advances in basic and clinical research, this multifactorial process, promoted by a myriad of risk factors, continues to be the greatest health burden on our society (23). Understanding atherosclerotic plaque microstructure in relation to molecular mechanisms that underlie its initiation, progression and clinical consequences, is required to provide the best chance of combating it.

Histologically atherosclerosis begins with focal thickening 
of the intima of large and medium-sized arteries with accumulation of dendritic cells, lymphocytes, lipid-laden macrophages or foam cells, and extracellular matrix. It is the early accumulation of lipids that produces the fatty streak. Fibroatheroma evolves from the fatty streak with progressive accumulation of smooth muscle cells, connective tissue and a deeper extracellular lipid pool, with more advanced lesions often containing a necrotic lipid-rich core. Intra-plaque hemorrhage is a common histological feature of advanced atherosclerotic lesions and is a critical element to the development of plaque instability, which may lead to plaque rupture and thrombosis (23). Fundamentally, atherosclerosis is an inflammatory disease process beginning in the endothelium that is precipitated by increased levels of circulating oxidized low-density lipoprotein (LDL) (23). Macrophages that have taken up oxidized LDL release a variety of inflammatory substances, cytokines and growth factors $(24,25)$; including monocyte chemotactic protein-1 (26), intracellular adhesion molecule-1 (27), interleukins (28) and tumor necrosis factor alpha (29). Pro-inflammatory cytokines enhance expression of cell surface molecules to adhesion molecules, induce cell proliferation, contribute to the production of reactive oxygen species and stimulate matrix metalloproteinases (MMP) which promote plaque rupture $(24,25)$.

\section{Mechanisms of plaque complication leading to acute coronary syndrome (ACS)}

ACS predominantly results from two distinct plaque complications-rupture and erosion-that lead to thrombosis and manifest as unstable angina, acute myocardial infarction (MI), or sudden cardiac death (30). Plaque rupture is most frequent, accounting for $60-75 \%$ of ACS cases (31-33). It typically develops in a lesion with a necrotic core and a thin, overlying fibrous cap. Following disruption of the macrophage and T-lymphocyte infiltrated fibrous cap, a luminal thrombus develops due to physical interaction between platelets and the thrombogenic necrotic core (33). Although research into the mechanism of plaque rupture is ongoing, it is widely believed that disruption occurring at the fibrous cap is associated with systemic activation of adaptive immunity (34). While necrotic core expansion and positive remodeling may be associated with plaque progression and lesion vulnerability, breakdown of extracellular matrix proteins by secreted MMPs are believed to be the predominant mechanistic pathway resulting in degradation of the fibrous cap (35). Healed lesions can occur at sites of prior rupture and thrombus formation (36). Healed ruptures are responsible for a small minority of ACS cases and frequently exhibit multiple layers of necrotic cores interspersed by fibrous tissue (37). In a minority of patients, plaque rupture is determined by local mechanisms rather than by diffuse activation of inflammatory cells. Fibrocalcific plaques can penetrate the lumen and disrupt the luminal surface, with little or no underlying necrotic core (30).

In contrast, plaque erosion is characterized by the absence of endothelium rather than fibrous cap disruption $(38,39)$. Typically, most eroded lesions lack a necrotic core and have a thick fibrous cap. The primary cellular characteristics of eroded plaques include an abundance of smooth muscle cells and proteoglycan matrix, with few macrophages and T-lymphocytes seen close to the lumen (40). Mechanistic observations indicate that these plaques lead to a disturbance of flow resulting in toll-like receptor-2 activation, recruitment of neutrophils, and subsequent promotion of de-endothelialization. This allows flowing blood to come in contact with plaque collagen resulting in a neutrophil-rich thrombus formation $(41,42)$.

\section{Role of intravascular imaging in detecting vulnerable plaque}

The term 'vulnerable plaque' was initially used in 1989 by Muller et al. to describe plaques that are predisposed to spontaneous rupture and cause clinical sequelae (43). Pathological studies have identified that plaques with a specific phenotype including a thin fibrous cap $(<65 \mu \mathrm{m})$, a large lipid pool, and activated macrophages near the fibrous cap, are at increased risk of rupture and therefore vulnerable $(30,31,44)$. Thin-cap fibroatheroma (TCFA) was first described by Kolodgie et al. and is considered the major precursor lesion for ACS (45). Notably, retrospective studies have revealed that most atherosclerotic plaques responsible for ACS cause only mild stenoses angiographically $(46,47)$, highlighting the deficiencies of an imaging modality that fails to provide any evaluation of the plaque residing within the arterial wall. Despite the improved prognosis for ACS patients treated with pharmacologic therapies and PCI (48-50), recurrent MACE occur in a substantial proportion of cases. Several prospective clinical studies have investigated the potential for intracoronary imaging to identify vulnerable plaques and those patients at risk of suffering repeat cardiovascular events (51-57). 


\section{IVUS}

The PROSPECT (Providing Regional Observations to Study Predictors of Events in the Coronary Tree) and VIVA (VH-IVUS in Vulnerable Atherosclerosis) studies were the first to use three-vessel grayscale and radiofrequency IVUS imaging to examine its efficacy in detecting nonculprit vulnerable plaque. In PROSPECT, 697 patients with ACS underwent IVUS and VH-IVUS imaging after PCI (51). During a median follow-up period of 3.4 years, the cumulative rate of MACE was $20.4 \%$. Atherosclerotic lesions with a minimum lumen area $\leq 4 \mathrm{~mm}^{2}$, a $\mathrm{PB} \geq 70 \%$ and VH-IVUS defined TCFA phenotype (requiring $>10 \%$ confluent necrotic core on three consecutive frames and an arc of necrotic core in contact with the lumen surface for $\geq 36^{\circ}$, highlighting the inadequate spatial resolution of IVUS to identify thin fibrous cap) were eleven times more likely to cause MACE than simple lesions (hazard ratio, 11.05, $\mathrm{P}<0.001)$. However, the positive-predictive value (PPV) for these high-risk plaque features for future events was low (18.2\%). In the VIVA study, 170 patients with stable angina or ACS undergoing PCI had a total of 1,096 plaques classified (52). Over a median follow-up of 625 days, 19 lesions resulted in MACE (13 non-culprit and 6 culprit). Non-culprit lesion factors associated with increased nonrestenotic MACE included VH-TCFA (hazard ratio, 7.53, $\mathrm{P}=0.038$ ) and $\mathrm{PB}>70 \%$ (hazard ratio, $8.13, \mathrm{P}=0.011$ ). $\mathrm{On}$ a patient-based analysis, only 3-vessel non-calcified $\mathrm{VH}$ TCFA was associated with increased non-restenotic MACE (hazard ratio, 1.79, $\mathrm{P}=0.004$ ).

In the ATHEROREMO-IVUS (European Collaborative Project on Inflammation and Vascular Wall Remodeling in Atherosclerosis- Intravascular Ultrasound) study, 581 patients undergoing CAG for ACS or stable angina had single, non-culprit vessel VH-IVUS imaging (53). Patients with a TCFA lesion phenotype and an increased $\mathrm{PB}(>70 \%)$ had an increased incidence of MACE at 12-month followup. However, the MACE rate was low, as was the PPV (23\%) of these plaque features and it was impossible to determine whether VH-IVUS provided further prognostic information beyond clinical risk factors. In the PREDICTION (Prediction of Progression of Coronary Artery Disease and Clinical Outcome Using Vascular Profiling of Shear Stress and Wall Morphology) study, vascular profiling CAG and IVUS were used to reconstruct each artery and calculate endothelial shear stress (ESS) and plaque characteristics in vivo (54). Three-vessel vascular profiling was performed at baseline in 506 patients with ACS treated with PCI and again in a subset of $374(74 \%)$ consecutive patients 6 to 10 months later to assess plaque natural history. Clinical events were infrequent. Large plaque size and low ESS independently predicted the exploratory end points of increased PB and worsening, clinically relevant luminal obstructions. The combination of independent baseline predictors had a $41 \% \mathrm{PPV}$ and $92 \%$ negative-predictive value (NPV) to predict plaque progression.

The presence of plaque ultrasonic attenuation and intraplaque echolucency on grayscale IVUS have also been linked to increased cardiovascular events (58-60). Comparison with NIRS has shown that these IVUS characteristics are related to lipid content $(61,62)$, with the probability of lipid core highest in attenuated plaques and the risk of biologic instability greatest with superficial rather than deep plaque attenuation (62).

Taken together, IVUS-based studies demonstrate that TCFA, high PB and superficial plaque attenuation are each characteristics of vulnerable plaques that are at high-risk of future atherothrombotic events, aligning well with data from histological post-mortem studies $(30,31,44)$. However, their results also highlight that the presence of these features individually or collectively, carries disappointing PPV for future MACE, controverting the utility of IVUS in routine clinical practice for identifying high-risk lesions.

\section{OCT}

Conventional ultrasonic imaging lacks the resolution to reliably distinguish individual plaque components currently considered to be determinants of vulnerability. Lipid-rich TCFAs are more unstable and prone to rupture and can be identified and quantitated by OCT. The relationship between culprit site LRP and cardiovascular events has been documented in patients with ACS utilizing OCT $(63,64)$. A retrospective trial established that OCT-detected non-culprit LRP led to a two-fold increase in non-culprit MACE (hazard ratio, 2.06, $\mathrm{P}=0.036$ ), primarily driven by revascularization for recurrent ischemia (65). OCT has also been used to identify macrophages, that exert a central role in plaque destabilization by releasing proteolytic enzymes and other pro-inflammatory mediators (55). Di Vito et al. applied OCT to quantify macrophage burden in coronary plaques by using tissue property indexes, particularly normalized standard deviation (NSD) and granulometry index (66). However, other groups have questioned the specificity of the methods used and highlight the fact that macrophages comprise heterogeneous pro-inflammatory 
and anti-inflammatory subtypes that have diverse atherogenic and protective roles in plaque formation, which are not able to be distinguished by OCT (67).

In the CLIMA (relationship between Coronary pLaque morphology of the left anterior descending artery and long terM clinicAl outcome) study, 1,003 patients undergoing CAG were subjected to OCT imaging of the proximal left anterior descending coronary artery (56). Cardiac death and target vessel MI was almost eight-fold higher in patients who had plaques with a TCFA phenotype, lipid arc $>180^{\circ}$, minimum lumen area $<3.5 \mathrm{~mm}^{2}$ and macrophage accumulation, compared to those that did not have any of these high-risk plaque characteristics (18.9\% vs. 3.0\%). Therefore, like IVUS, OCT had excellent NPV (97\%) when high-risk characteristics were absent, but poor PPV (19\%) even when all high-risk features were present. More recently, an automated OCT image processing algorithm was used in 42 patients undergoing elective PCI to enhance the external elastic lamina (EEL) contour and potentially improve measurement of $\mathrm{PB}$ compared to standard OCT (68). Pearson's correlation coefficients between IVUS and standard OCT measurements of PB were 0.61, 0.67, $0.76,0.78$ and 0.87 for fibroatheromas, mixed plaques, fibrocalcific plaques, fibrous plaques, and pathological intimal thickening, respectively. These correlation coefficients increased to $0.81,0.83,0.83,0.84$ and 0.94 when using the EEL-enhanced OCT images $(\mathrm{P}=0.003, \mathrm{P}=0.004$, $\mathrm{P}=0.08, \mathrm{P}=0.13$ and $\mathrm{P}=0.23$, respectively). In comparison with conventional OCT, the EEL-enhanced OCT images had a higher sensitivity $(79 \%$ vs. $28 \%, \mathrm{P}<0.001)$ and specificity ( $98 \%$ vs. $85 \%, \mathrm{P}=0.03)$ for detecting plaques with an IVUS PB $\geq 70 \%$ (Figure 2).

While the largest body of evidence indicates that atherosclerosis results from intimal accumulation of lipids and inflammatory cells, recent studies suggest that vascular inflammation begins in the adventitia and subsequently enters the media and intima from the outside of the vessel wall $(69,70)$. The vasa vasorum (VV), a network of microvasculature originating in the adventitia are a primary site of response to vessel wall injury or insult. In atherosclerosis, the $\mathrm{VV}$ undergo expansion and infiltration into plaque, carrying with them inflammatory cells $(69,70)$. The VV have also been demonstrated to play a role in plaque instability. Necropsy studies in patients who had died suddenly from coronary causes identified an increase in microvascular density associated with intraplaque hemorrhage (71). Taruya et al. utilized frequency-domain OCT (FD-OCT) to highlight the relationship between the VV increase and plaque vulnerability (72). Fifty-three patients underwent FD-OCT and were classified into five groups according to lesion characteristics: normal; fibrous plaque; fibroatheroma; plaque rupture; and fibrocalcific plaque. Signal-poor tubuloluminal structures in the adventitial layer were defined as VV, and within plaque as intraplaque neovessels. In the fibrous plaque group, the VV volume positively correlated with overall plaque volume $(\mathrm{R}=0.71, \mathrm{P}<0.01)$. This correlation was thought to be the consequence of the $\mathrm{VV}$ restructuring which allows increased oxygen and nutrients to reach the vessel wall from the adventitia, promoting plaque progression. The intraplaque neovessels volume modestly correlated with plaque volume in the fibroatheroma and plaque rupture groups $(\mathrm{R}=0.53, \mathrm{P}=0.04)$, demonstrating an association with plaque vulnerability. Imaging for microvasculature could therefore provide a new means of determining plaque vulnerability.

Increasing evidence suggests that the presence of cholesterol crystals (CCs) within plaque also increases its vulnerability, both by inducing inflammatory responses in plaque macrophages and neutrophils and by causing mechanical injury to the fibrous cap (73). FD-OCT enables visualisation of CCs in vivo which manifest as a thin, linear region of high signal intensity within the lipid plaque (74). OCT was implemented in a study of 250 patients with stable CAD to investigate for a relationship between CCs and other parameters of plaque vulnerability. Three hundred and thirty vessels containing 263 non-culprit and 113 culprit plaques were imaged prior to culprit lesion PCI. Thirtynine point six percent of patients had at least one CC in the culprit plaque, and this was associated with larger lipid arc $\left(179.8^{\circ} \pm 72.1^{\circ}\right.$ for plaques with CCs vs. $111.1^{\circ} \pm 65.6^{\circ}$ for those without, $\mathrm{P}=0.001)$ and a greater frequency of TCFA (30.3\% vs. $2.1 \%, \mathrm{P}=0.01$ ) (74). Non-culprit plaques with CCs present also displayed other high-risk characteristics, including larger mean lipid arc, smaller fibrous cap thickness, and higher prevalences of TCFA, microchannel and plaque rupture than lesions with no CC present.

\section{Dual modality imaging}

The limited efficacy of grayscale IVUS, VH-IVUS and OCT imaging in predicting lesions that will undergo future atherothrombotic events is partly based on their respective limitations in detecting plaque composition and has led to evaluation of dual modality NIRS-IVUS imaging. NIRS has predominantly been used to quantitate lipid content within plaques. LRPs were first defined on NIRS as a lipid 

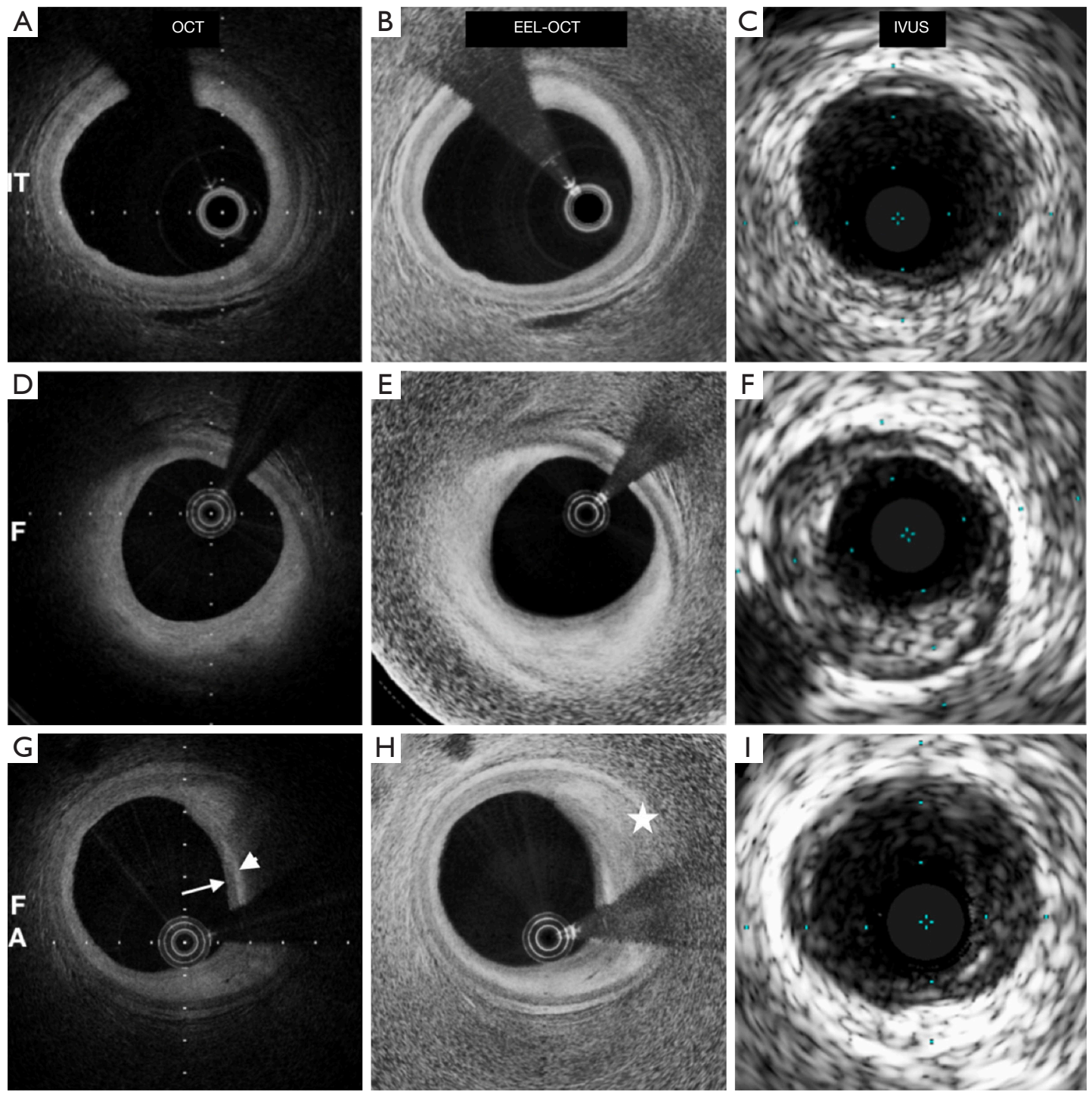

Figure 2 Comparison of standard intracoronary imaging modalities with corresponding EEL-enhanced OCT. (A) OCT image of pathological intimal thickening; (B) corresponding EEL-enhanced OCT image enabling improved visualization of the EEL; (C) corresponding IVUS image of pathological intimal thickening; (D) OCT image of fibrous plaque; (E) corresponding EEL-enhanced OCT image revealing more EEL around the arterial circumference; (F) corresponding IVUS image of fibrous plaque; (G) OCT image of fibroatheroma plaque; $(\mathrm{H})$ corresponding EEL-enhanced OCT image enabling improved visualization of the EEL deep to the plaque; (I) corresponding IVUS image of fibroatheroma plaque. Key; thin-cap fibroadenoma (arrow), lipid rich pool (arrowhead), EEL (star), intimal thickening (IT), fibrous plaque (F), fibroadenoma (FA). [Images adapted with permission from Gerbaub et al. (68)]. IVUS, intravascular ultrasound; OCT, optical coherence tomography; EEL, external elastic lamina.

core $>60^{\circ}$ in circumferential extent with $>200 \mu \mathrm{m}$ depth and an overlying fibrous cap thickness $<450 \mu \mathrm{m}$ (75). A commonly used quantification of the lipid burden is the LCBI which is derived by dividing the number of yellow pixels by the total number of pixels available, multiplied by 1,000 (LCBI ranges from 0 to 1,000 ). The $\mathrm{LCBI}_{4 \mathrm{~mm}}$ quantifies the greatest regions of LRP within the target region, divided into $4 \mathrm{~mm}$ coronary segments (76). Adding NIRS to conventional IVUS-derived PB in 116 coronary vessels in 51 autopsied hearts demonstrated that a combined $\mathrm{PB}$ and LCBI analysis significantly improved fibroatheroma detection accuracy (c-index $0.77, \mathrm{P}=0.028 v s$. $\mathrm{PB}$ alone). 
In vivo comparisons of 43 age- and sex-matched patients yielded similar associations to those demonstrated ex vivo (6). In a number of cross-sectional studies, NIRS has identified large LRP at culprit sites in a majority of patients with ACS (77-79). Numerous prospective trials have demonstrated that either a high LCBI or $\mathrm{LCBI}_{4 \mathrm{~mm}}$ is a strong predictor of MACE $(57,80,81)$. Oemrawsingh et al. measured NIRSderived LCBI within a non-culprit vessel in 203 patients referred for angiography for stable angina pectoris or ACS and found that patients with an LCBI greater than the median of 43.0 had a four-fold increased risk of MACE during 1 year follow-up (16.7\% vs. $4.0 \%$, hazard ratio, 4.04 , $\mathrm{P}=0.01)$ (57). Madder et al. showed that the presence of NIRS-determined large LRP, defined as maximum LCBI in $4 \mathrm{~mm} \geq 400$, increased risk of subsequent major adverse cardiovascular and cerebrovascular events (MACCE) (82). The LRP (Lipid-Rich Plaque Study of vulnerable plaques and vulnerable patients) study evaluated the efficacy of NIRS-IVUS in detecting vulnerable plaque. The study enrolled 1,241 patients with stable angina (46.3\%) or ACS (53.7\%) and assessed $>5,000$ lesions. The presence of LRP ( $\left.\mathrm{LCBI}_{4 \mathrm{~mm}} \geq 400\right)$ was associated with a four-fold higher event rate (hazard ratio 4.11, $\mathrm{P}<0.001$ ). Further, for each 100 unit increase of max $\mathrm{LCBI}_{4 \mathrm{~mm}}$, the risk of nonculprit MACE increased by $18 \%$, and patients with max $\mathrm{LCBI}_{4 \mathrm{~mm}} \geq 400$ were at $87 \%$ higher risk of non-culprit MACE at 24-month follow-up (83). The ATHEROREMONIRS substudy of 203 patients showed that plaque composition, in particular an increased LCBI was associated with worse prognosis (57). Ongoing studies including PROSPECT II (NCT02171065) will utilize IVUS and NIRS to test the potential value of vulnerable plaque detection.

Integrated, dual modality imaging was similarly used in a first-in-man study in which simultaneous intracoronary OCT and NIRAF image data were obtained from 12 patients undergoing PCI (19). High NIRAF signal was elevated in plaques with a high-risk morphological phenotype, specifically TFCA, regions of cap disruption, and in-stent restenosis (ISR). By contrast, NIRAF signal was negative or low in plaques with a low-risk microstructural phenotype as determined by OCT. High intensity NIRAF was limited to plaque regions that showed OCT evidence of macrophage accumulation. The study highlighted that multimodality technologies combining microstructural and fluorescence imaging can potentially improve the capacity to predict plaque vulnerability and refine patient and lesion specific risk (Figure 3).

\section{Summary}

Thus far all intravascular evaluation of high-risk plaque has demonstrated excellent NPV but poor PPV and further studies are needed to evaluate the incremental benefit of intracoronary imaging over clinically derived risk stratification and guidance of treatment. Furthermore, imaging based characterization of vulnerable plaques has almost entirely been performed in the framework of identifying features predictive of plaque rupture and this may not be applicable to identifying plaques at risk of erosion, known to be responsible for $25-40 \%$ of ACS (30). Conventional IVUS imaging lacks sufficient resolution to detect impairment of endothelial cells. However, Jia et al. showed that OCT has the capability to identify erosion (84). Recently a novel microscopic imaging technology, termed micro-optical coherence tomography $(\mu \mathrm{OCT})$, that offers a resolution of $1 \mu \mathrm{m}$ has been used successfully in a porcine model to enable endothelial cell visualization (85) and may play a future role in better understanding the pathogenesis of ACS caused by plaque erosion.

\section{Intravascular imaging in spontaneous coronary dissection}

Spontaneous Coronary Artery Dissection (SCAD) is also becoming an increasingly recognized cause of ACS particularly among women under 50 years of age where the prevalence of SCAD has been reported to be as high as $8.7 \%$, increasing to $10.8 \%$ in the subgroup with STelevation myocardial infarction (STEMI) (86).

Hemorrhage into the tunica media from $\mathrm{VV}$ has been suggested as a possible mechanism of SCAD (87) but only recently has OCT provided a suitable imaging tool to evaluate this (88). OCT was used to evaluate 9 consecutive patients with SCAD and 18 gender-matched control subjects with non-obstructive CAD at a median of 44 days after index presentation (89). Plaque volume was defined as intimal volume plus medial volume and divided by lesion length to provide an adjusted volume (cubic millimeters/ millimeter). Patients with SCAD demonstrated higher overall $\mathrm{VV}$ volume $\left(0.47 v s .0 .19 \mathrm{~mm}^{3} / \mathrm{mm}, \mathrm{P}<0.001\right)$ and almost a five-fold greater VV density than those with nonobstructive CAD. These findings raise the possibility that extravasation of blood from proliferative adventitial VV may lead to the formation of microhematomas between the media and intima that could result in coronary dissection. Further studies are needed to determine the causal 

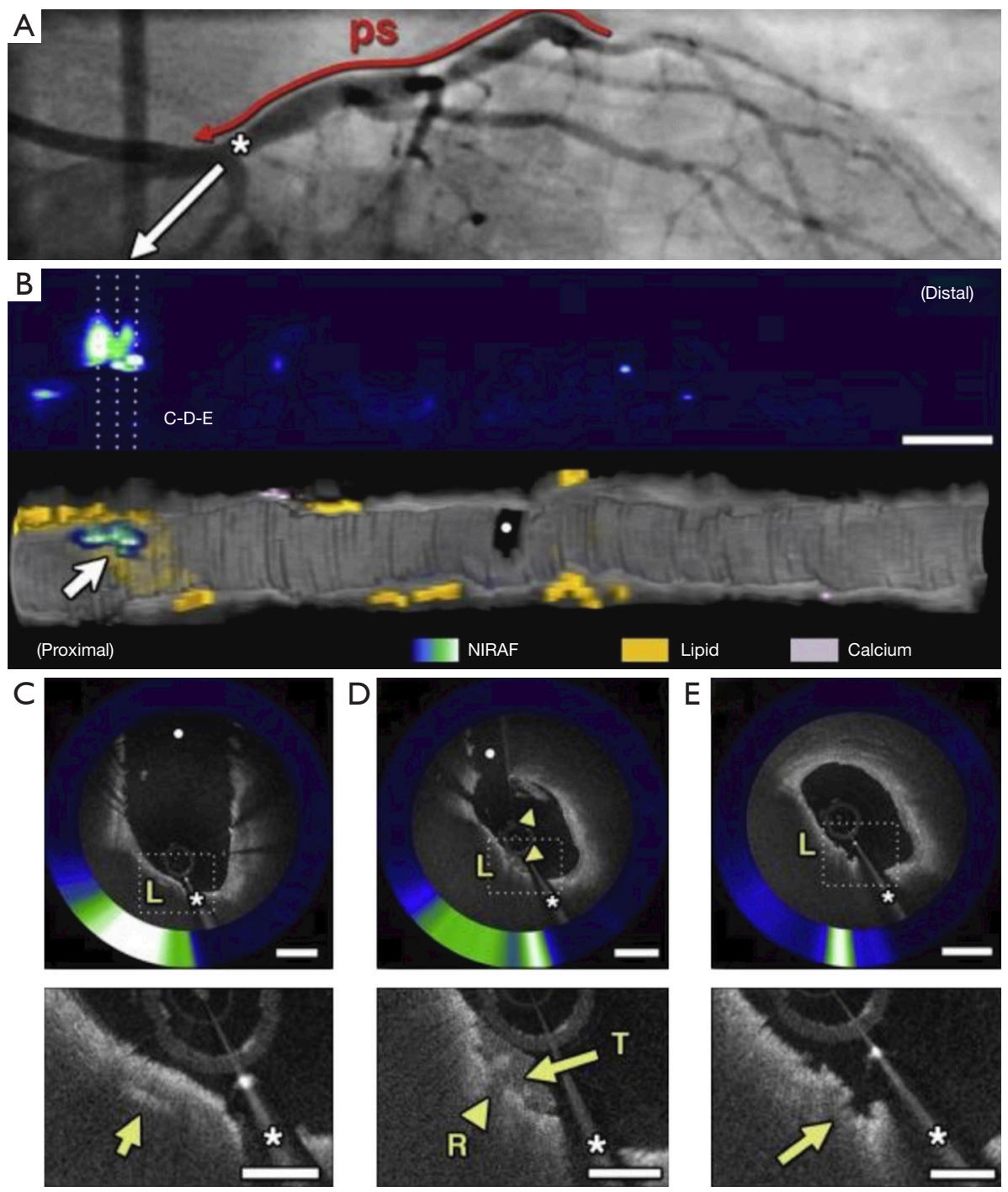

Figure 3 Integrated OCT and NIRAF imaging of a TCFA. (A) Coronary angiogram of the left anterior descending artery; (B) NIRAF map identifying a focal region of elevated NIRAF in the ostial left anterior descending artery, and below, the three-dimensional cutaway rendering demonstrating the highest NIRAF spot appears focally within a lipid pool; (C,D,E) OCT and NIRAF cross sections from sites in the ostial left anterior descending artery revealing subclinical fibrous cap rupture. Key: *, guide-wire shadowing artifact; OCT showing white luminal thrombus (arrow), plaque rupture (R), thrombus (T). [Images adapted with permission from Ughi et al. (19)]. OCT, optical coherence tomography; NIRAF, near-infrared autofluorescence; TCFA, thin-cap fibroatheroma.

relationship between the VV and the pathogenesis of SCAD and intravascular imaging will provide invaluable insights.

\section{Role of intravascular imaging in therapeutic modulation of atherosclerosis}

The imaging techniques described above have also been used to evaluate established therapies for their ability to modulate coronary atherosclerosis (Table 1 ). The most significant body of work has employed serial IVUS imaging following cholesterol-lowering treatment with $\beta$-hydroxy $\beta$-methylglutaryl-CoA (HMG-CoA) reductase inhibitors, or statins. Increasingly, new medical therapies, particularly those that target plaque inflammation, are also 


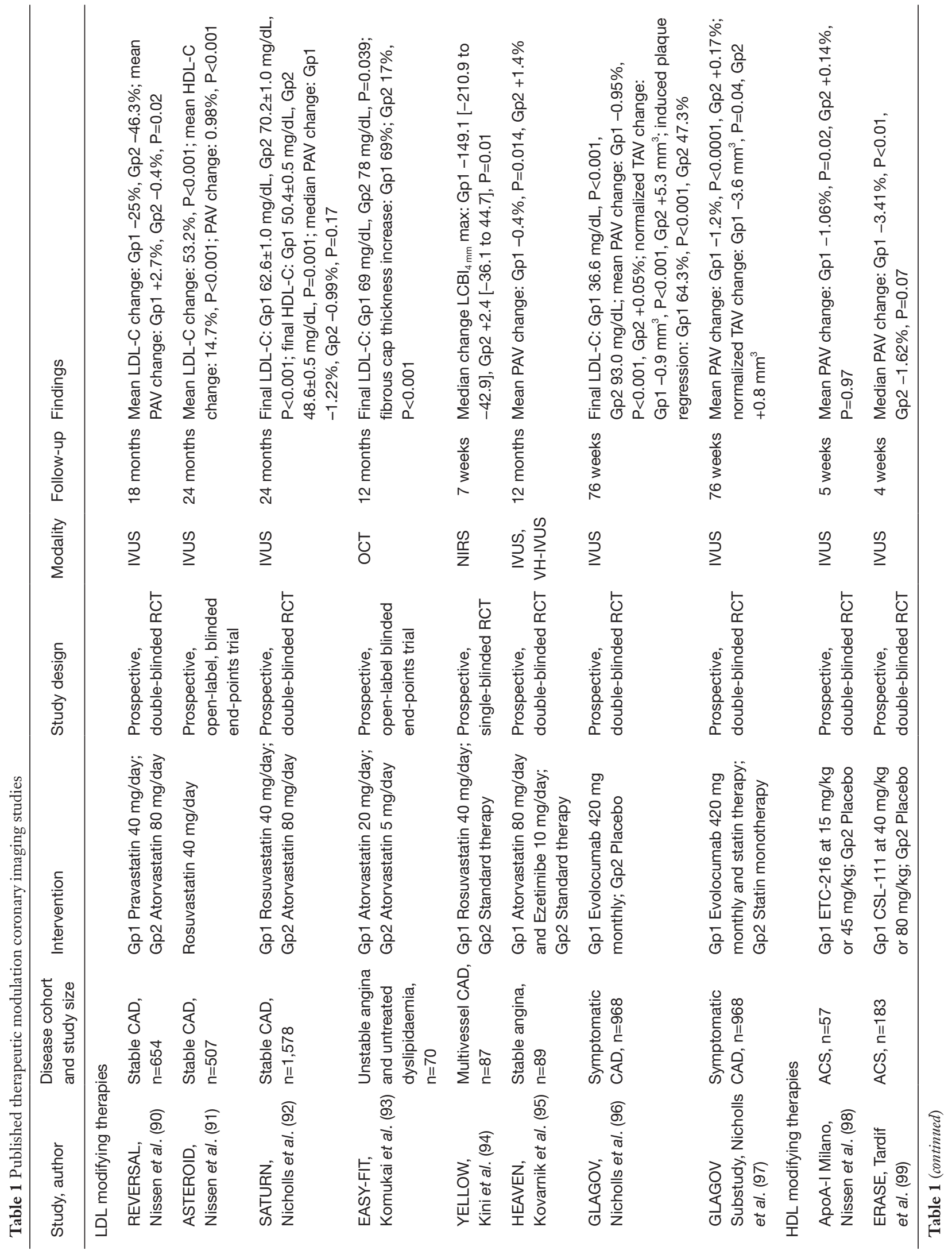




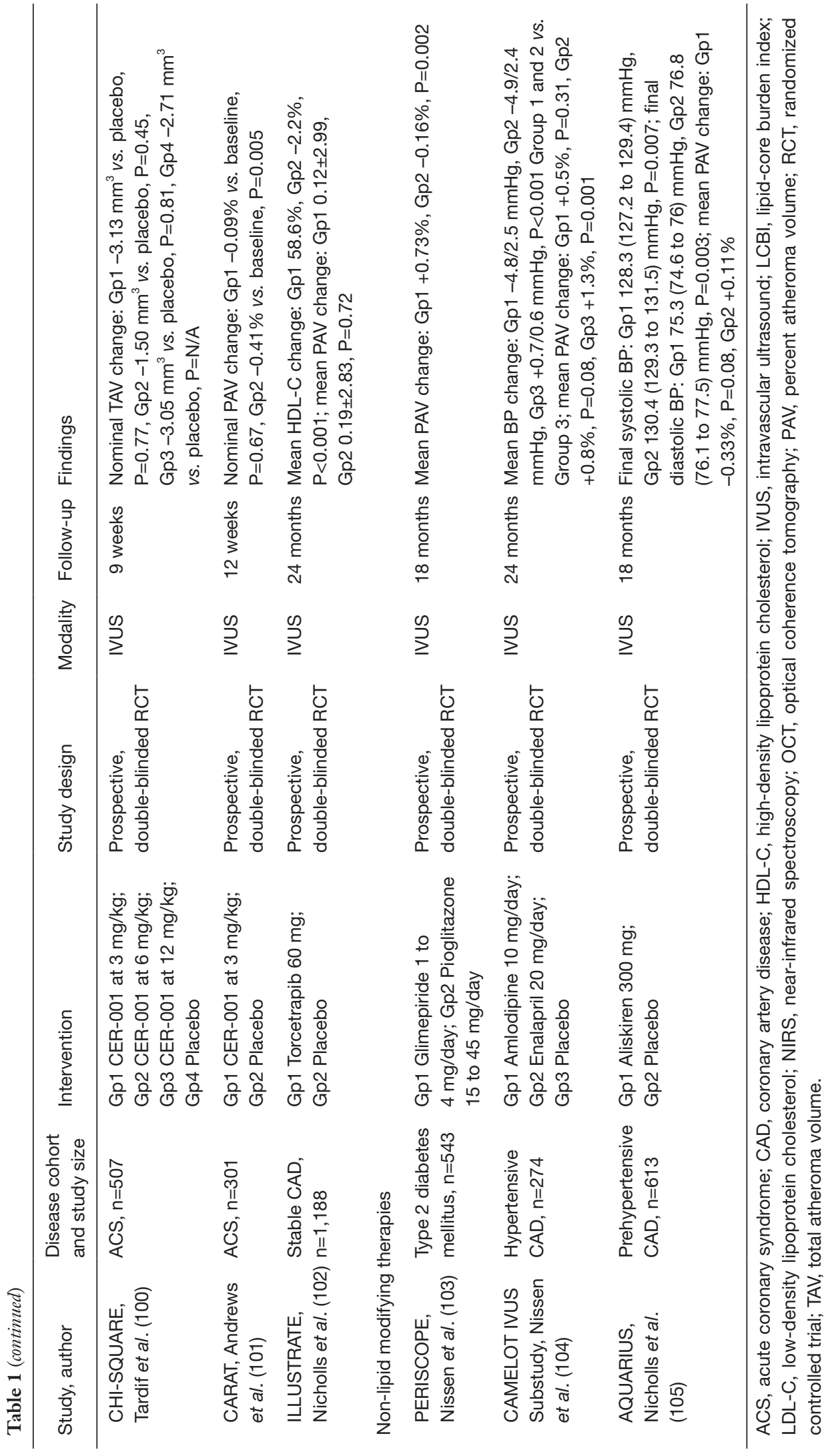


being evaluated.

\section{Targeting LDL cholesterol (LDL-C)}

The correlation between lowering levels of LDL-C and reduction of MACCE rates is well established (106). Serial IVUS coronary imaging has demonstrated that lowering LDL-C with high intensity statin therapy reduces atherosclerotic PB. The REVERSAL (Reversal of Atherosclerosis with Aggressive Lipid Lowering) study compared moderate lipid-lowering with pravastatin $40 \mathrm{mg}$ and intensive lipid-lowering with atorvastatin $80 \mathrm{mg}$ for 18 months (90). Baseline LDL-C levels (mean $3.9 \mathrm{mmol} / \mathrm{L}$ or $150.2 \mathrm{mg} / \mathrm{dL})$ were reduced to $2.8 \mathrm{mmol} / \mathrm{L}(110 \mathrm{mg} / \mathrm{dL})$ in the pravastatin group compared with $2 \mathrm{mmol} / \mathrm{L}$ $(79 \mathrm{mg} / \mathrm{dL})$ in the atorvastatin group $(\mathrm{P}<0.0001)$. The inflammatory biomarker C-reactive protein (CRP) decreased $5.2 \%$ with pravastatin and $36.4 \%$ with atorvastatin $(\mathrm{P}<0.001)$. For all IVUS endpoints, progression occurred in the moderate treatment arm, and PV was unchanged in the intensive arm. Direct relationships were shown between the degree of LDL-C lowering, slowing of disease progression and reduction of CRP (107).

Very high intensity statin therapy was further investigated to assess its ability to alter progression of $\mathrm{PB}$ in the ASTEROID (a study to evaluate the effect of rosuvastatin on intravascular ultrasound-derived coronary atheroma burden) trial (91). Three hundred and fortynine patients who received $40 \mathrm{mg}$ daily rosuvastatin had baseline and 24-month IVUS examinations. Rosuvastatin therapy resulted in a mean reduction of LDL-C of $53 \%$ and an increase in high-density lipoprotein cholesterol (HDL-C) of $15 \%$. Significant plaque regression was observed with a $6.8 \%$ median reduction in total atheroma volume (TAV). The SATURN (study of coronary atheroma by intravascular ultrasound: effect of rosuvastatin versus atorvastatin) trial was an extension of ASTEROID and compared rosuvastatin $40 \mathrm{mg} /$ day directly to atorvastatin $80 \mathrm{mg}$ /day for 24 months (92). The rosuvastatin group achieved lower levels of LDL-C than the atorvastatin group [1.62 vs. $1.82 \mathrm{mmol} / \mathrm{L}$ (62.6 vs. $70.2 \mathrm{mg} / \mathrm{dL}$ ), $\mathrm{P}<0.001]$, and higher levels of HDL-C [1.30 vs. $1.26 \mathrm{mmol} / \mathrm{L}$ (50.4 vs. $48.6 \mathrm{mg} / \mathrm{dL}$ ), $\mathrm{P}=0.01$ ]. Despite these small differences in the post treatment lipid profiles, plaque regression was similar in both treatment arms, occurring in two thirds of participants. Treatment reduced plaque progression in all subgroups irrespective of baseline lipoprotein levels (108). Additional analysis of these IVUS-based studies have also revealed that statins stabilize atherosclerotic plaques and are pro-calcific regardless of net plaque change, with the greatest increase in calcium associated with higher intensity therapy (109).

Alternative imaging modalities have assessed the modifying effect of statin therapy on atherosclerotic plaque composition. Serial OCT of non-culprit lesions was used in 70 patients with unstable angina and dyslipidemia in the Japanese EASY-FIT study to investigate plaque stability. Patients were randomized to $20 \mathrm{or} 5 \mathrm{mg}$ of atorvastatin daily and imaging was performed at baseline and 1-year follow-up (93). Lower LDL-C levels were achieved in the higher dose group (69 vs. $78 \mathrm{mg} / \mathrm{dL}, \mathrm{P}=0.039$ ) with OCT suggesting a more stable plaque in this group, characterized by a significant increase in fibrous cap thickness of $69 \%$ compared to $17 \%(\mathrm{P}<0.001)$. The increase in fibrous cap correlated with the decrease in LDL-C levels and grade of OCT measured macrophages.

Similar results were seen in a single center study that examined the effects of the addition of ezetimibe $10 \mathrm{mg}$ daily to treatment with fluvastatin $30 \mathrm{mg}$ daily. The reduction in LDL-C was significantly larger in the group receiving combination therapy $(-34.0 \pm 32.0$ vs. $-8.8 \pm 17.4 \mathrm{mg} / \mathrm{dL}$, $\mathrm{P}<0.001)$, and while OCT demonstrated a significant increase in fibrous cap thickness after 9 months of therapy in both groups, this was greater in those receiving combination therapy (110). In the HEAVEN study, 89 patients with stable angina were randomized to aggressive lipid lowering therapy of atorvastatin $80 \mathrm{mg}$ and ezetimibe $10 \mathrm{mg}$ daily or standard statin therapy over 12 months after which coronary arteries were examined by IVUS and VHIVUS (95). Although combination therapy resulted in an increased frequency of atherosclerotic regression, manifest as increased lumen volume and decreased percent atheroma volume (PAV) (40.5\%) compared with standard therapy $(14.9 \%)(\mathrm{P}=0.007)$, VH-IVUS identified no difference between the two arms with respect to plaque composition. Both groups showed a shift to higher risk morphology during the treatment period with a decrease in fibrous and fibro-fatty tissue and an increase in necrotic core and dense calcification. This demonstrates that although aggressive LDL-C lowering therapy can result in plaque regression, it does not invariably stabilize plaque composition to eradicate atherothrombotic risk.

The YELLOW (Reduction in Yellow Plaque by Intensive Lipid Lowering Therapy) trial was an open labeled study that utilized NIRS and IVUS to compare the impact of short-term intensive statin therapy on 
lipid content of atherosclerotic plaque (94). Imaging was conducted at baseline and on completion of 7 weeks of treatment with either rosuvastatin $40 \mathrm{mg}$ daily or standardof-care lipid lowering therapy. Intensive therapy was associated with a larger mean reduction in $\mathrm{LCBI}_{4 \mathrm{~mm}}$ max (LCBI at the $4 \mathrm{~mm}$ maximal segment) measured by NIRS [-149.1 ( -210.9 to -42.9$)$ vs. 2.4 ( -36.1 to 44.7$), \mathrm{P}=0.01]$. Importantly, the baseline LCBI was significantly greater in those randomized to the intensive treatment group. Despite significant LCBI reduction, neither arm demonstrated a difference in PB percentage measured by IVUS. In the subsequent YELLOW II (reduction in coronary yellow plaque, lipids and vascular inflammation by aggressive lipid lowering) study, 85 patients with stable symptomatic multivessel CAD underwent PCI of a culprit lesion, followed by intracoronary multimodal imaging, including NIRS, IVUS and OCT, of an obstructive non-culprit lesion. All patients were given rosuvastatin daily for 8 to 12 weeks, when the non-culprit lesion was reimaged. The study demonstrated a reduction in TCFA prevalence from $20.0 \%$ to $7.1 \%$ $(\mathrm{P}=0.003)$ consistent with plaque stabilization (111).

More recently, the effect on plaque microstructure of alternative LDL-C lowering therapies has also been evaluated using intracoronary imaging. Proprotein convertase subtilisin kexin type 9 (PCSK9) reduces LDL receptor recycling to the hepatic surface, thereby limiting removal of LDL particles from the circulation (112-114). Monoclonal antibodies against PCSK9 reduce LDL-C (115). The GLAGOV (global assessment of plaque regression With a PCSK9 antibody as measured by intravascular ultrasound) trial randomized 968 moderateor-high dose statin-treated patients to PCSK9 inhibition with monthly evolocumab or placebo for 76 weeks. Compared with placebo, the evolocumab group achieved lower LDL-C levels (93.0 vs. $36.6 \mathrm{mg} / \mathrm{dL}, \mathrm{P}<0.001)$. Serial IVUS revealed that PAV increased $0.05 \%$ with placebo and decreased $0.95 \%$ with evolocumab $(\mathrm{P}<0.001)$. Furthermore, evolocumab was associated with a greater reduction in normalized TAV $\left(-0.9\right.$ vs. $\left.5.8 \mathrm{~mm}^{3}, \mathrm{P}<0.001\right)$ and induced plaque regression in a greater percentage of patients (47.3 vs. $64.3 \%, \mathrm{P}<0.001$ for $\mathrm{PAV}$ and 48.9 vs. $61.5 \%$, $\mathrm{P}<0.001$ for TAV). The failure of approximately one-third of evolocumab treated patients to display atheroma regression despite achieving very low LDL-C levels suggests that other factors are also contributing to disease progression (96). Further IVUS analysis of GLAGOV patients revealed that the addition of evolocumab did not produce differential changes in plaque composition compared with statin monotherapy.
In particular, no differences were observed between the evolocumab and placebo groups in changes in calcium (1.0 00.3 vs. $\left.0.6 \pm 0.3 \mathrm{~mm}^{3}, \mathrm{P}=0.49\right)$, fibrous $(-3.0 \pm 0.6$ vs. $\left.-2.4 \pm 0.6 \mathrm{~mm}^{3}, \mathrm{P}=0.49\right)$, fibrofatty $\left(-5.0 \pm 1.0 v s .-3.0 \pm 1.0 \mathrm{~mm}^{3}\right.$, $\mathrm{P}=0.49)$ and necrotic $\left(-0.6 \pm 0.5\right.$ vs. $\left.-0.1 \pm 0.5 \mathrm{~mm}^{3}, \mathrm{P}=0.49\right)$ volumes (97).

Collectively, these predominantly IVUS-based studies demonstrate a direct association between the extent of LDL-C lowering and disease progression, irrespective of baseline lipoprotein levels (92). Over a 12- to 18-month period, plaques typically stop progressing at LDL-C levels below $1.8 \mathrm{mmol} / \mathrm{L}$, and at levels below $1.3 \mathrm{mmol} / \mathrm{L}$ show signs of regression with significant reduction in TAV and PAV. Furthermore, some of these studies also demonstrate the beneficial effect of LDL-C lowering on plaque stability, with an increase in fibrous cap thickness, reduction in TCFA prevalence and mean reduction in $\mathrm{LCBI}_{4 \mathrm{~mm}}$, demonstrable within 12 months of treatment initiation.

\section{Targeting HDL cholesterol (HDL-C)}

Evidence suggests that HDL-C plays a protective role in atherosclerosis. Population studies demonstrate an inverse relationship between HDL-C and prospective cardiovascular events (116). Lower levels of HDL-C correlate with increased cardiovascular events despite very low LDL-C levels (117). This has encouraged the development of therapies targeting HDL-C including the infusion of delipidated HDL which in both preclinical and clinical trials has been identified to have pleiotropic beneficial effects on atherosclerotic burden, including via promotion of cholesterol efflux (118) and improved endothelial cell function (119).

Niacin remains a practical and effective treatment to increase low HDL-C levels in clinical practice. A small study utilizing serial IVUS imaging compared the effects of a combination of niacin and simvastatin to simvastatin monotherapy on plaque regression (120). There were no intergroup differences for normalized TAV or PAV at baseline or on completion of nine months of therapy. However, the degree of change in both parameters was greater in the combination compared to the monotherapy arm $(\triangle \mathrm{TAV}$ : $-21.6 \pm 10.7$ vs. $5.5 \pm 42.2 \mathrm{~mm}^{3}, \mathrm{P}=0.024 ; \triangle \mathrm{PAV}:-1.2 \% \pm 2.5 \%$ vs. $-0.6 \% \pm 5 \%, \mathrm{P}=0.047)$. Whether this translates to clinical benefit has been questioned, as a recent trial showed no additive reduction in cardiovascular events when extendedrelease niacin was used in statin-treated patients (121).

The potential benefit of infusing lipid-deplete forms of 
HDL to modify coronary plaque has been investigated in multiple IVUS studies $(98,99,122,123)$. In the first of these, intravenous infusions of reconstituted HDL containing apoA-1 Milano (AIM) or placebo (saline) were administered to patients post-ACS (98). IVUS imaging was conducted at baseline and after 5 weeks of treatment, and rapid regression of atherosclerotic plaque was demonstrated in patient's receiving AIM infusions. Interestingly, this was not associated with a change in lumen size, supporting the concept that plaque regression is associated with reverse remodeling of the arterial wall (122). In the subsequent ERASE (The Effect of rHDL on Atherosclerosis Safety and Efficacy) trial, four weekly infusions of HDL particles containing wild-type apoA-1 were not associated with a significant difference in coronary atheroma volume evaluated by IVUS, when compared to saline placebo (99).

More recently, an engineered HDL-mimetic comprised of recombinant human apoA-I and phospholipids and designed to mimic the benefits of nascent pre- $\beta$ HDL (Cerenis Therapeutics, Labège, France, CER-001), was administered in the Chi-Square (can HDL infusions significantly quicken atherosclerosis regression?) trial. Patients were assigned three different doses of CER-001 or saline administered over 6 weekly infusions. CER-001 failed to significantly regress coronary atherosclerosis on IVUS when compared to placebo (100). In the subsequent CER001 Atherosclerosis Regression Acute Coronary Syndrome Trial (CARAT), 301 post-ACS patients were randomized to receive a series of 10 infusions of CER-001 at a dose of $3 \mathrm{mg} / \mathrm{kg}$ or placebo with IVUS used to assess the primary endpoint of median change in PAV. There was no difference between CER-001 treated and placebo-treated patients $(-0.09 \%$ vs. $-0.41 \%, \mathrm{P}=0.15)(101)$.

The development of cholesteryl ester transfer protein (CETP) inhibitors has also impacted the HDL field. As CETP promotes the transfer of cholesteryl esters from HDL to lipoproteins, including LDL and VLDL particles, inhibition of CETP results in raised HDL-C levels (124). This, together with the observation that populations with a high prevalence of low CETP activity, accompanied by high HDL-C levels, have fewer cardiovascular events has driven clinical interest in this drug group (125). The effect of the CETP inhibitor, torcetrapib, on atherosclerosis has been studied in several imaging trials. The ILLUSTRATE (Investigation of Lipid Level Management Using Coronary Ultrasound to Assess Reduction of Atherosclerosis by CETP Inhibition and HDL Elevation) study utilized IVUS to evaluate the effect of torcetrapib on atheroma progression in patients treated with atorvastatin for an LDL-C goal of $100 \mathrm{~g} / \mathrm{dL}$. Torcetrapib-treated patients showed a $61 \%$ relative increase in HDL-C concentrations and a $20 \%$ relative decrease in LDL-C levels when compared to atorvastatin monotherapy. Despite this, torcetrapib did not result in slowing of disease progression or promotion of disease regression, with no significant difference demonstrated in the change in atheroma volume within the most diseased vessel segment (126). However, a post-hoc analysis of ILLUSTRATE revealed an inverse relationship between the degree of HDL-C increase in torcetrapib-treated patients and the rate of atherosclerotic progression, with the highest HDL-C levels associated with plaque regression (102). In any case, torcetrapib's toxicity profile has prevented its uptake into clinical practice (127).

In summary, clinical outcome studies have mostly failed to demonstrate any tangible reduction in cardiovascular risk with HDL-C raising therapies. Furthermore, approaches promoting HDL functionality as opposed to its quantity have been equally disappointing. It follows that imagingbased studies have generally demonstrated inconsistent, non-significant trends in plaque regression, determined by TAV and PAV, and no clear benefit on plaque stabilization with agents that target HDL. Despite these disappointing results, the development of HDL infusion programs continues and alternative approaches to improve HDL functionality, such as up-regulating endogenous expression of apoA-I to generate functional, newly formed HDL particles, are being explored (128). Alternating macrophage polarization from a pro-inflammatory to anti-inflammatory phenotype may provide a further opportunity for HDL therapies to modify plaque favorably. The use of hybrid atherosclerotic imaging techniques with the ability to distinguish individual plaque components accurately will help to evaluate these therapies.

\section{Targeting triglycerides}

Another therapeutic target is triglyceride-rich lipoprotein particles that have potent atherogenic effects (129). Despite strong evidence that elevated triglyceride levels predict patients at increased risk of vascular risk (130), there is so far a paucity of information on the ability of triglyceride-lowering drugs to modulate coronary atheroma in human patients.

\section{Targeting diabetes}

It is predicted that type 2 diabetes mellitus will become 
the leading cause of mortality worldwide by 2020 (131). Patients with diabetes have a substantially increased risk of adverse cardiovascular events (132) and suffer less favorable outcomes post-MI (133) and following coronary interventions (134). Patients with diabetes exhibit greater $\mathrm{PB}$, increased atherosclerotic disease progression in the arterial wall and more frequent impaired compensatory remodeling leading to adverse plaque events than patients without diabetes (135). In addition, patients with diabetes have generally demonstrated greater increases in atheroma volume despite aggressive lowering of LDL-C levels (135). However, analysis of the IVUS-based SATURN trial demonstrated similar regression of atherosclerotic plaque independent of diabetes status, when on-treatment LDL-C levels were $\leq 70 \mathrm{mg} / \mathrm{dL}(-1.09 \% \pm 0.16 \%$ vs. $-1.24 \% \pm 0.16 \%$, $\mathrm{P}=0.50$ ). In contrast, disease regression was greater in the patients without diabetes when achieved LDL-C levels were $>70 \mathrm{mg} / \mathrm{dL}(-0.31 \% \pm 0.23 \%$ vs. $-1.01 \% \pm 0.21 \%, \mathrm{P}=0.03)$, highlighting the importance of tight lipid control in this context (136).

Peroxisome proliferation-activated receptor gamma $(\operatorname{PPAR} \gamma)$ agonists are utilized in some patients with diabetes, acting as insulin sensitizers. PPAR $\gamma$ activation may have multiple beneficial effects on atherogenesis, including reducing inflammation, improving endothelial function, and inhibiting apoptosis and oxidative stress. The PERISCOPE (pioglitazone effect on regression of intravascular sonographic coronary obstruction prospective evaluation) study compared pioglitazone, a PPAR $\gamma$ agonist, and glimepiride, a sulfonylurea, in diabetic patients (103). Coronary atheroma was assessed with IVUS at baseline and after completing 18 months of therapy. PAV increased $0.73 \%$ (95\% CI, $0.33 \%$ to $1.12 \%$ ) with glimepiride and decreased $0.16 \%$ ( $95 \% \mathrm{CI},-0.57 \%$ to $0.25 \%$ ) with pioglitazone $(\mathrm{P}=0.002)$. Pioglitazone treatment was associated with a significant HDL-C level increase (5.7 vs. $0.9 \mathrm{mg} / \mathrm{dL}, \mathrm{P}<0.001)$ and a median triglyceride level decrease $(-16.3$ vs. $3.3 \mathrm{mg} / \mathrm{dL}, \mathrm{P}<0.001)$, along with improvement in glycemic control. Further analysis discovered that raising the HDL-C was the strongest independent predictor of the capability of pioglitazone to slow plaque progression (137).

Although the clinical cardiovascular benefits of sodiumglucose co-transporter-2 inhibitors (138-140) and glucagonlike peptide-1 receptor agonists (141-143) have been well demonstrated in patients with diabetes, the effect of these agents on coronary atheroma is yet to be evaluated with intracoronary imaging. Meanwhile, the incremental benefit of achieving optimal control of multiple risk factors in patients with diabetes was demonstrated in an IVUSbased study which showed that increasing the number of risk factors meeting treatment targets was associated with slowing of progression of both PAV $(\mathrm{P}=0.03)$ and TAV $(\mathrm{P}<0.001)(144)$.

Atherosclerotic plaques in patients with diabetes have more advanced risk profiles than plaques from patients without diabetes. These IVUS-based studies demonstrate that these differences will continue to progress unless LDL-C levels below $1.8 \mathrm{mmol} / \mathrm{L}$ (or $70 \mathrm{mg} / \mathrm{dL}$ ) are achieved, and co-existent cardiovascular risk factors are treated optimally. Future imaging studies will help provide a mechanistic understanding of the differential effects that lipid-lowering agents have on plaque composition and stability in diabetic compared to non-diabetic patients (96), as well as the plaque-modifying properties of different classes of diabetic drugs.

\section{Blood pressure lowering}

Hypertension remains a key risk factor in the development of cardiovascular disease. Lowering of blood pressure in hypertensive patients provides similar relative protection at all levels of baseline cardiovascular risk but progressive greater absolute risk reduction as baseline risk increases (145). Although the evidence for clinical benefit in blood pressurelowering therapies is well established, the benefit of antihypertensive treatments on atherosclerotic coronary disease progression is not. The CAMELOT (comparison of amlodipine versus enalapril to limit occurrences of thrombosis) study evaluated the effect of amlodipine, enalapril and placebo on clinical event rates in patients with established CAD and well controlled blood pressure (104). Its IVUS substudy demonstrated that amlodipine pharmacotherapy both slowed atherosclerotic disease progression and lowered cardiovascular event rates. A trend towards atheroma regression was seen in patients who had attained a systolic $\mathrm{BP}<120 \mathrm{mmHg}$, implying a direct relationship between systolic blood pressure control and plaque progression (146). Despite pre-clinical data showing that activation of the renin-angiotensin-aldosterone system is atherogenic (147) and that its inhibition may be anti-atherosclerotic (148), this has not been supported by the limited evidence available from clinical imaging studies. Notably, the AQUARIUS (Aliskiren quantitative atherosclerosis regression intravascular ultrasound study) study failed to show any effect of the direct renin inhibitor, 
aliskerin, on IVUS-based metrics of plaque progression in patients with prehypertension (105).

\section{Targeting lifestyle}

Madssen et al. investigated the effects of aerobic interval training (AIT) compared to moderate continuous training (MCT) on coronary atherosclerotic disease in patients with significant $\mathrm{CAD}$ and recent intracoronary stent implantation (149). Patients were randomized to AIT or MCT for 12 weeks after PCI. Grayscale and VH-IVUS were performed at baseline and follow-up. Both modes of exercise were associated with a $10.7 \%$ decrease in $\mathrm{PB}$, and similar reductions in necrotic core size. To date, the effects of other lifestyle interventions, including smoking cessation and weight reduction, have not been investigated comprehensively.

\section{Targeting inflammation}

The central role that inflammation plays in all stages of atherosclerosis has led to increasing evaluation of both new and repurposed anti-inflammatory agents for the treatment of CAD (150). The CANTOS (canakinumab antiinflammatory thrombosis outcomes study) trial provided a major stimulus in the field by showing a reduction in composite MACE in post-MI patients with residual inflammatory risk (defined by high sensitivity CRP $>2 \mathrm{mg} / \mathrm{L}$ ) who were treated with the anti-IL-1 $\beta$ monoclonal antibody, canakinumab (151). Although the CIRT (cardiovascular inflammation reduction trial) trial failed to achieve similar benefits from low-dose methotrexate (152), the recent COLCOT (colchicine cardiovascular outcomes trial) study demonstrated that repurposing of low-dose colchicine $(0.5 \mathrm{mg} /$ day) led to a $23 \%$ MACE reduction when initiated in addition to standard antiplatelet and statin therapy within 30 days of an MI (153). The ongoing OCT-based COCOMO-ACS study (ACTRN12618000809235) will inform on whether colchicine modifies coronary $\mathrm{PB}$ and composition to help understand the mechanistic basis for this striking result.

\section{Ongoing therapeutic modulation coronary imaging studies}

Multiple trials utilizing vessel wall-based imaging modalities to evaluate the responsiveness to established and experimental therapeutic interventions are ongoing (Table 2). Hybrid modalities are also increasingly being used to merge structural imaging with targeting of more specific molecular factors within plaque and may further assist in our understanding of the factors driving the natural history of disease, risk stratification and evaluation of therapies.

\section{Role of intravascular imaging in PCI}

\section{Coronary stent restenosis and thrombosis}

Coronary artery stents are used in the vast majority of patients who undergo PCI, but vessel patency may not be maintained due to either restenosis or stent thrombosis. In-stent restenosis (ISR) is the result of arterial damage with resultant neointimal proliferation which occurs in association with macrophage accumulation, smooth muscle cell hyperplasia and extensive neovascularization (154). The rate of ISR has been reported to be between $3 \%$ and $20 \%$, depending on stent-type, duration of followup, patient comorbidities and the complexity of stented lesions (155). Stent thrombosis is a frequent life-threatening complication that can occur acutely (within 24 hours), sub-acutely (within 30 days), or as late as 1 year (late) or more (very late) after stent placement and can be can be a potentially life-threatening complication $(156,157)$. Most cases occur within the first 30 days irrespective of stent type (158). Registry data indicate that the cumulative incidence of stent thrombosis with drug-eluting stents (DES) at 1 year is approximately $0.4 \%$ to $0.8 \%$ (159). In clinical trial populations, the risk has been estimated at $0.2 \%$ to $0.3 \%$ per year after the first year for at least 5 years (160). Pathologic studies suggest that very late stent thrombosis (VLST) is due to delayed neointimal coverage and ongoing vessel inflammation $(161,162)$ and that the presence of greater than $30 \%$ of uncovered struts is highly predictive of stent thrombosis following DES implantation (161). Compared with paclitxel-eluting stents (PES), sirolimuseluting stents (SES), or zotarolimus-eluting stents (ZES), everolimus-eluting stents (EES) significantly reduce the risk of stent thrombosis, suggesting they facilitate arterial healing (158). The apposition of DES struts to the arterial wall is also correlated to strut coverage, with malapposition resulting in delayed coverage compared with wellapposed struts (163). Neoatherosclerosis, first described in postmortem studies, is a recently recognized phenomenon in which LRP develop within pre-existing stents, and represents an emerging cause of VLST (164-166). Coronary imaging modalities which are vessel wall-based and have the ability to determine stent strut coverage, strut apposition 


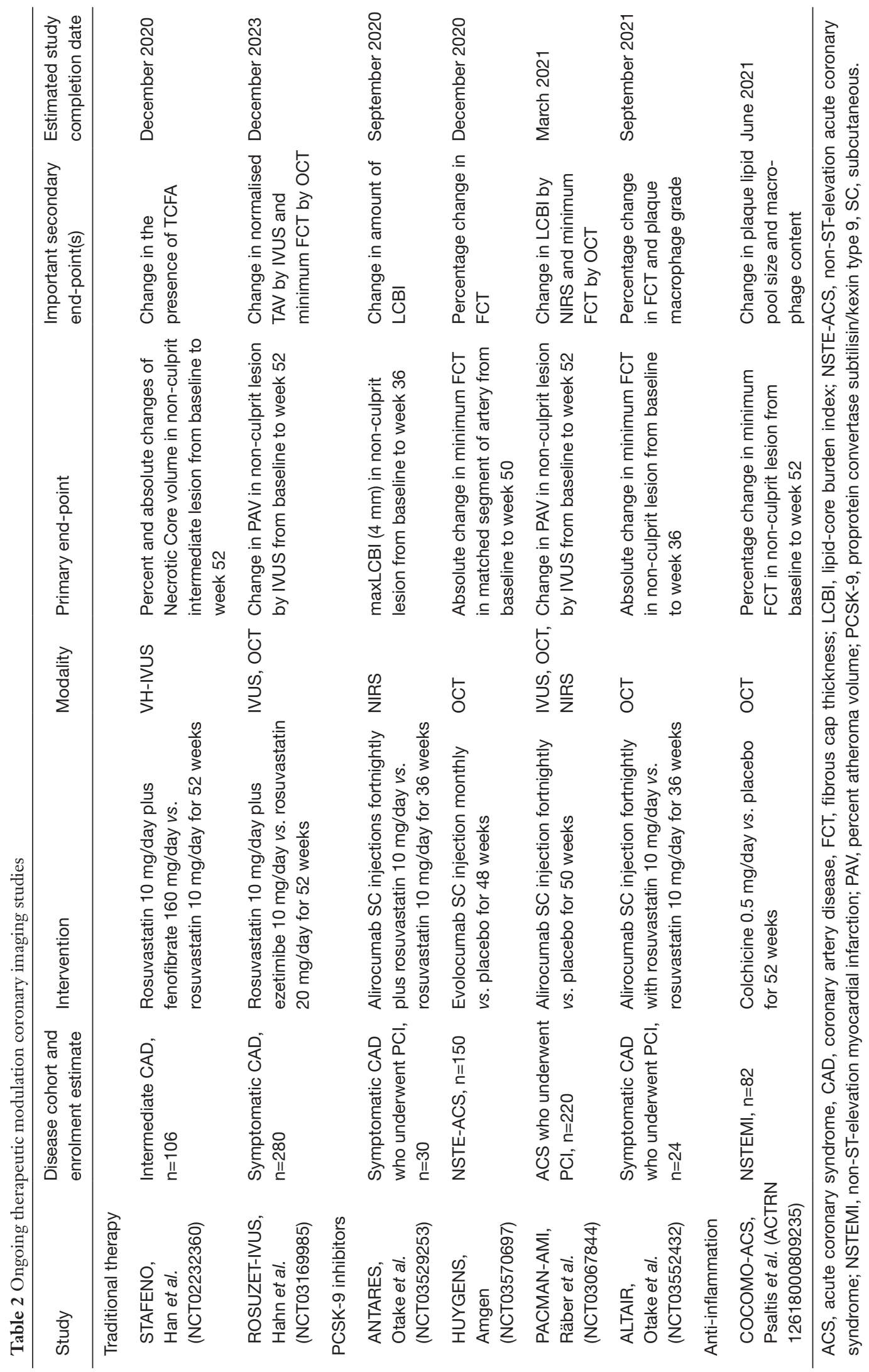


and detect LRP have an important part to play in clinical practice, with both IVUS and OCT used for this purpose.

In an early case-controlled study, Guagliumi et al. investigated 54 patients, including 18 with DES late stent thrombosis (LST) undergoing emergency PCI and 36 matched DES control subjects undergoing repeat OCT and IVUS three or more years after stent insertion (167). In patients with LST, OCT demonstrated a higher percentage of uncovered $(12.27 \%$ vs. $4.14 \%, \mathrm{P}<0.001)$ and malapposed struts $(4.6 \%$ vs. $1.81 \%, \mathrm{P}=0.028)$ and IVUS demonstrated an increase in positive remodeling (mean vessel crosssection area $19.4 \pm 5.8$ vs. $\left.15.1 \pm 4.6 \mathrm{~mm}^{2}, \mathrm{P}=0.003\right)$. Stent expansion was comparable in the two groups. OCT determined percentage of uncovered stent struts and IVUS determined remodeling index were found to be independent predictors of LST. Due to its superior axial and lateral resolution, OCT has been found to be superior to IVUS in terms of both detecting stent expansion and strut apposition at deployment (168) and determining the prevalence of subsequent stent coverage (169).

Studies have utilized serial OCT to evaluate stent strut coverage and strut malapposition for different stent types, different time-points post stent deployment, and for different clinical indications. The OCT substudy of the HORIZONS-AMI (harmonizing outcomes with revascularization and stents in acute myocardial infarction) trial compared the TAXUS PES to an otherwise identical Express bare metal stent (BMS) in 118 consecutive patients with STEMI (170). The PES reduced neointimal hyperplasia but had an increased incidence of uncovered and malapposed stent struts compared with the BMS 13 months following stent implantation. This phenomenon is seen for most DES which suppress excessive neointima formation at a cost of delaying stent strut healing. The OCT substudy of the LEADERS (Limus eluted from a durable versus erodable stent coating) trial found that stent coverage at a mean follow up of nine-months was more complete in patients after deployment of biodegradable polymer-coated, biolimus-eluting stents (BES) in comparison to the durable polymer-coated SES but that the coverage was similar after 24 months ( $1.5 \%$ vs. $1.8 \%$ uncovered stent struts) $(171,172)$.

The OCT substudy of the RESOLUTE Allcomers (Randomised, Two-arm, Non-inferiority Study Comparing Endeavor-Resolute Stent With Abbot Xience-V Stent) trial demonstrated no significant differences in either stent strut tissue coverage and malapposition at 13-month follow-up between the hydrophilic polymercoated ZES (Resolute) and the fluropolymer-coated EES (Xience) (7.4\% vs. 5.8\% uncovered stent struts) (173). Intracoronary OCT imaging trials have demonstrated a higher rate of uncovered and malapposed stent struts in DES when implanted during a STEMI in comparison to patients with stable CAD (174-176).

OCT may also potentially assist in determining the different tissues covering stent struts, notably fibrin coverage with thrombotic material as opposed to neointimal coverage, with a lower OCT signal intensity typically observed for fibrin-covered stent struts $(177,178)$. The presence of OCT-determined thin rim coverage likely to represent fibrin was reported in a high percentage of stent struts 3-7 days after successful use of cobalt chromium and first generation DES, with potential implications for increased stent thrombosis (179).

NIRS has been validated for the purpose of LRP detection in native coronary vessels (180) and has been proposed as a method to demonstrate neoatherosclerosis within pre-existing coronary stents. This has important clinical implications as neoatherosclerosis and rupture can result in VLST. Madder et al. used NIRS and IVUS in a cohort with pre-existing stents $(5.5 \pm 4$ years earlier) and a control group of freshly implanted stents. Although NIRS detected LRP signal within 20 of 60 pre-existing stents, 7 of these had no evidence of neointimal tissue on IVUS. Moreover, NIRS findings in pre-existing stents were indistinguishable from those of freshly implanted stents with regards to both LCBI and $\mathrm{LCBI}_{4 \mathrm{~mm}}$. Therefore, the detection of LRP in a pre-existing stent by NIRS alone was determined to be unreliable evidence of neoatherosclerosis as the lipid signal may originate from fibroatheroma underlying the stent. Accurate diagnosis of neoatherosclerosis within stents remains a challenge for current intracoronary imaging modalities.

All considered, these studies demonstrate that IVUS- and OCT-based intracoronary imaging can provide information about the completeness and nature of stent strut coverage which can vary between stent types and differing drugeluting platforms, and the extent of stent malapposition. These serve as surrogate safety endpoints which can predict real clinical outcomes, such as LST and restenosis. The studies also highlight the failure of current vessel-wall based imaging modalities to accurately detect neoatherosclerosis, a potential cause of VLST. 


\section{Determining optimal duration of dual antiplatelet therapy (DAPT)}

Trials with clinical endpoints have so far supported shorter duration of DAPT with new generation DES $(181,182)$. Intracoronary imaging may theoretically help to guide the optimal duration of DAPT for individual patients. The DETECT-OCT (determination of the duration of dual antiplatelet therapy by the degree of the coverage of the struts on optical coherence tomography from the randomized comparison between everolimus-eluting stents versus biolimus A9-eluting stents) trial explored the feasibility of stopping DAPT early based on the extent of strut coverage evaluated by 3 -month OCT in 894 patients undergoing PCI with DES (183). In a 2-by-2 factorial design, patients were randomized to EES or BES and to OCT- or angiographically-guided stent implantation. Despite variance in polymer composition, strut thickness and antiproliferative drug pharmacokinetics, no significant difference in strut coverage was identified between the groups (median percentage of uncovered struts, $8.9 \%$ and $8.2 \%, \mathrm{P}=0.69$ ). However, OCT-guided stent deployment improved strut coverage at three months (median percentage of uncovered struts was $7.5 \%$ in the OCT-guided group and $9.9 \%$ in the angiographically-guided group, $\mathrm{P}=0.009$ ). Favorable early strut coverage (defined as $\leq 6 \%$ uncovered) was observed in $41.1 \%$ of patients and resulted in discontinuation of clopidogrel. Subsequently, at 12 months the composite of cardiac death, MI, stent thrombosis and major bleeding was not significantly different between those who received 3 and 12 months of DAPT, as guided by OCT ( $0.3 \%$ vs. $0.2 \%, \mathrm{P}=0.80$ ).

In the RevElution first-in-human trial, 100 patients with de novo coronary lesions $2.25-3.50 \mathrm{~mm}$ in diameter and $\leq 27 \mathrm{~mm}$ in length were randomized to either a polymerfree drug filled stent or a ZES (Resolute) with IVUS-based assessment at nine or 24 months, and OCT follow-up in a subset of 30 patients at multiple time periods. The primary endpoint was angiographic in-stent late lumen loss at nine months compared with historical data from the Resolute stent as a control. The study showed that the polymer-free drug filled stent was non-inferior to Resolute for late lumen loss $(0.26 \pm 0.28$ vs. $0.36 \pm 0.52 \mathrm{~mm})$. Median stent strut coverage by OCT was $91.4 \%, 95.6 \%$, and $99.1 \%$ at one, three and nine months, respectively, potentially allowing for a shorter duration of DAPT (184).

\section{Summary and future perspectives}

The use of intracoronary imaging modalities has greatly advanced our understanding of the full extent, composition and rate of progression of atherosclerotic coronary plaques. They have helped determine the characteristics of plaque that make it vulnerable and predispose patients to increased risk of future atherothrombotic events. Further, studies using these modalities serially have provided helpful mechanistic information about the responsiveness of coronary atherosclerosis to established and experimental pharmacotherapies and lifestyle interventions. Some of these strategies, most notably LDL-C lowering drugs, have clearly been shown to not only slow plaque growth, but also induce plaque regression and stabilization at high doses. Meanwhile, the anti-atherosclerotic properties of other treatments (e.g., HDL-raising approaches) have been less conclusive, commensurate with the lack of benefit also seen in clinical outcome trials. As new therapies are tested to address the unacceptable residual burden associated with $\mathrm{CAD}$, intracoronary imaging will continue to play an important role in evaluating their effectiveness against atherosclerosis, to support or caution against their uptake into clinical practice. As these imaging modalities become more advanced to combine anatomical with biological information, they will also help to identify new cellular and molecular targets for anti-atherosclerotic agents. This should also lead to better targeting of pathological substrates in plaque that are not specifically addressed by current treatments, such as plaque neovascularization, hemorrhage and erosion.

Information from the use of these modalities has also served to corroborate pathological findings relating to coronary stent healing and risk of thrombosis. This has already impacted significantly on clinical practice with regards to stent choice, vigilance required to ensure optimal stent strut apposition and, increasingly, determination of the optimal duration for DAPT post-stent deployment. The opportunity exists to use these same modalities to evaluate new pharmacotherapies to promote early and more complete strut coverage with neointima rather than fibrin and to prevent LRP formation within stents to further reduce the risk of stent thrombosis.

Moving forward, coronary imaging studies using vessel wall-based techniques may also provide insight into poorly understood but frequently encountered CAD processes. These include non-atherosclerotic SCAD, myocardial infarction with non-obstructive coronary disease (MINOCA), and aggressive atherosclerotic CAD that progresses despite good control of traditional risk factors. Ultimately, the goal should be for intracoronary imaging to 
be used safely, efficiently and effectively in these and other settings, to facilitate personalized diagnostic, prognostic and therapeutic decision making on the way to delivering better patient outcomes.

\section{Acknowledgments}

The authors thank Mr. Giuseppe DiGiovanni from the Atherosclerotic Imaging Core Laboratory, South Australian Health and Medical Research Institute for assistance with image preparation.

Funding: AJN receives personal funding from the National Heart Foundation and the Royal Australian College of Physicians. SJN receives a Principal Research Fellowship from the National Health and Medical Research Council (NHMRC) of Australia (ID1111630). PJP receives a L2 Future Leader Fellowship from the National Heart Foundation of Australia (FLF102056) and L2 Career Development Fellowship from the NHMRC (CDF1161506).

\section{Footnote}

Provenance and Peer Review: This article was commissioned by the Guest Editor (Dennis T. L. Wong) for the series "Intracoronary Imaging" published in Cardiovascular Diagnosis and Therapy. The article was sent for external peer review organized by the Guest Editor and the editorial office.

Conflicts of Interest: All authors have completed the ICMJE uniform disclosure forms (available at http:// dx.doi.org/10.21037/cdt-20-1). The series "Intracoronary Imaging" was commissioned by the editorial office without any funding or sponsorship. SJN reports grants from AstraZeneca, Amgen, Anthera, Eli Lilly, Esperion, Novartis, Cerenis, The Medicines Company, Resverlogix, InfraReDx, Roche, Sanofi-Regeneron and LipoScience, personal fees from AstraZeneca, Akcea, Eli Lilly, Anthera, Omthera, Merck, Takeda, Resverlogix, Sanofi-Regeneron, CSL Behring, Esperion, Boehringer Ingelheim, outside the submitted work. In addition, SJN has a patent as a named inventor on a patent for the use of PCSK9 inhibitors and their impact on atherosclerotic plaque, Issued. PJP reports personal fees from ESPERION Therapeutics, Bayer, Boehringer Ingelheim, Merck, Pfizer, Astra Zeneca, grants from ABBOTT Vascular, outside the submitted work. SJN serves as an unpaid editorial board member of Cardiovascular
Diagnosis and Therapy from Jul 2019 to Jun 2021. PJP serves as an unpaid editorial board member of Cardiovascular Diagnosis and Therapy from Aug 2019 to Jul 2021. The authors have no other conflicts of interest to declare.

Ethical Statement: The authors are accountable for all aspects of the work in ensuring that questions related to the accuracy or integrity of any part of the work are appropriately investigated and resolved.

Open Access Statement: This is an Open Access article distributed in accordance with the Creative Commons Attribution-NonCommercial-NoDerivs 4.0 International License (CC BY-NC-ND 4.0), which permits the noncommercial replication and distribution of the article with the strict proviso that no changes or edits are made and the original work is properly cited (including links to both the formal publication through the relevant DOI and the license). See: https://creativecommons.org/licenses/by-nc-nd/4.0/.

\section{References}

1. Rubio DM, Schoenbaum EE, Lee LS, et al. Defining translational research: implications for training. Acad Med 2010;85:470-5.

2. Woolf SH. The meaning of translational research and why it matters. JAMA 2008;299:211-3.

3. Ballantyne CM. Clinical trial endpoints: angiograms, events, and plaque instability. Am J Cardiol 1998;82:5M-11M.

4. Keane D, Haase J, Slager CJ, et al. Comparative validation of quantitative coronary angiography systems. Results and implications from a multicenter study using a standardized approach. Circulation 1995;91:2174-83.

5. Nicholls SJ, Hsu A, Wolski K, et al. Intravascular ultrasound-derived measures of coronary atherosclerotic plaque burden and clinical outcome. J Am Coll Cardiol 2010;5 5:2399-407.

6. Puri R, Madder RD, Madden SP, et al. Near-Infrared Spectroscopy Enhances Intravascular Ultrasound Assessment of Vulnerable Coronary Plaque: A Combined Pathological and In Vivo Study. Arterioscler Thromb Vasc Biol. 2015;35:2423-31.

7. Lavoie AJ, Bayturan O, Uno K, et al. Plaque progression in coronary arteries with minimal luminal obstruction in intravascular ultrasound atherosclerosis trials. Am J Cardiol 2010;105:1679-83.

8. Nair A, Kuban BD, Tuzcu EM, et al. Coronary plaque 
classification with intravascular ultrasound radiofrequency data analysis. Circulation 2002;106:2200-6.

9. Jang IK, Bouma BE, Kang DH, et al. Visualization of coronary atherosclerotic plaques in patients using optical coherence tomography: comparison with intravascular ultrasound. J Am Coll Cardiol. 2002;39:604-9.

10. Kawasaki M, Bouma BE, Bressner J, et al. Diagnostic accuracy of optical coherence tomography and integrated backscatter intravascular ultrasound images for tissue characterization of human coronary plaques. J Am Coll Cardiol 2006;48:81-8.

11. Yabushita H, Bouma BE, Houser SL, et al. Characterization of human atherosclerosis by optical coherence tomography. Circulation 2002;106:1640-5.

12. Tearney GJ, Waxman S, Shishkov M, et al. Threedimensional coronary artery microscopy by intracoronary optical frequency domain imaging. JACC Cardiovasc Imaging. 2008;1:752-61.

13. Kume T, Akasaka T, Kawamoto T, et al. Assessment of coronary intima--media thickness by optical coherence tomography: comparison with intravascular ultrasound. Circ J 2005;69:903-7.

14. Kilic ID, Caiazzo G, Fabris E, et al. Near-infrared spectroscopy-intravascular ultrasound: scientific basis and clinical applications. Eur Heart J Cardiovasc Imaging 2015;16:1299-306.

15. Andrews J, Puri R, Kataoka Y, et al. Therapeutic modulation of the natural history of coronary atherosclerosis: lessons learned from serial imaging studies. Cardiovasc Diagn Ther 2016;6:282-303.

16. Lee S, Lee MW, Cho HS, et al. Fully integrated highspeed intravascular optical coherence tomography/nearinfrared fluorescence structural/molecular imaging in vivo using a clinically available near-infrared fluorescenceemitting indocyanine green to detect inflamed lipid-rich atheromata in coronary-sized vessels. Circ Cardiovasc Interv 2014;7:560-9.

17. Verjans JW, Osborn EA, Ughi GJ, et al. Targeted NearInfrared Fluorescence Imaging of Atherosclerosis: Clinical and Intracoronary Evaluation of Indocyanine Green. JACC Cardiovasc Imaging 2016;9:1087-95.

18. Kim JB, Park K, Ryu J, et al. Intravascular optical imaging of high-risk plaques in vivo by targeting macrophage mannose receptors. Sci Rep 2016;6:22608.

19. Ughi GJ, Wang H, Gerbaud E, et al. Clinical Characterization of Coronary Atherosclerosis With DualModality OCT and Near-Infrared Autofluorescence Imaging. JACC Cardiovasc Imaging 2016;9:1304-14.
20. Htun NM, Chen YC, Lim B, et al. Near-infrared autofluorescence induced by intraplaque hemorrhage and heme degradation as marker for high-risk atherosclerotic plaques. Nat Commun 2017;8:75.

21. Barquera S, Pedroza-Tobias A, Medina C, et al. Global Overview of the Epidemiology of Atherosclerotic Cardiovascular Disease. Arch Med Res 2015;46:328-38.

22. Go AS, Mozaffarian D, Roger VL, et al. Executive summary: heart disease and stroke statistics--2014 update: a report from the American Heart Association. Circulation 2014;129:399-410.

23. Galkina E, Ley K. Immune and inflammatory mechanisms of atherosclerosis $\left(^{*}\right)$. Annu Rev Immunol 2009;27:165-97.

24. Berliner JA, Navab M, Fogelman AM, et al. Atherosclerosis: basic mechanisms. Oxidation, inflammation, and genetics. Circulation 1995;91:2488-96.

25. Steinberg D, Witztum JL. Oxidized low-density lipoprotein and atherosclerosis. Arterioscler Thromb Vasc Biol 2010;30:2311-6.

26. Gawaz M, Neumann FJ, Dickfeld T, et al. Activated platelets induce monocyte chemotactic protein-1 secretion and surface expression of intercellular adhesion molecule-1 on endothelial cells. Circulation 1998;98:1164-71.

27. Takahashi M, Kitagawa S, Masuyama JI, et al. Human monocyte-endothelial cell interaction induces synthesis of granulocyte-macrophage colony-stimulating factor. Circulation 1996;93:1185-93.

28. Rectenwald JE, Moldawer LL, Huber TS, et al. Direct evidence for cytokine involvement in neointimal hyperplasia. Circulation 2000;102:1697-702.

29. Tintut Y, Patel J, Parhami F, et al. Tumor necrosis factoralpha promotes in vitro calcification of vascular cells via the cAMP pathway. Circulation. 2000;102:2636-42.

30. Virmani R, Kolodgie FD, Burke AP, et al. Lessons from sudden coronary death: a comprehensive morphological classification scheme for atherosclerotic lesions. Arterioscler Thromb Vasc Biol 2000;20:1262-75.

31. Falk E, Shah PK, Fuster V. Coronary plaque disruption. Circulation. 1995;92:657-71.

32. Davies MJ. Anatomic features in victims of sudden coronary death. Coronary artery pathology. Circulation 1992;85:I19-24.

33. Burke AP, Farb A, Malcom GT, et al. Plaque rupture and sudden death related to exertion in men with coronary artery disease. JAMA 1999;281:921-6.

34. Flego D, Liuzzo G, Weyand CM, et al. Adaptive Immunity Dysregulation in Acute Coronary Syndromes: From Cellular and Molecular Basis to Clinical Implications. J 
Am Coll Cardiol 2016;68:2107-17.

35. Angelini G, Flego D, Vinci R, et al. Matrix metalloproteinase-9 might affect adaptive immunity in non-ST segment elevation acute coronary syndromes by increasing CD31 cleavage on CD4+ T-cells. Eur Heart J 2018;39:1089-97.

36. Kubo T, Maehara A, Mintz GS, et al. The dynamic nature of coronary artery lesion morphology assessed by serial virtual histology intravascular ultrasound tissue characterization. J Am Coll Cardiol 2010;55:1590-7.

37. Burke AP, Kolodgie FD, Farb A, et al. Healed plaque ruptures and sudden coronary death: evidence that subclinical rupture has a role in plaque progression. Circulation 2001;103:934-40.

38. Arbustini E, Dal Bello B, Morbini P, et al. Plaque erosion is a major substrate for coronary thrombosis in acute myocardial infarction. Heart 1999;82:269-72.

39. Farb A, Burke AP, Tang AL, et al. Coronary plaque erosion without rupture into a lipid core. A frequent cause of coronary thrombosis in sudden coronary death. Circulation 1996;93:1354-63.

40. Kolodgie FD, Burke AP, Farb A, et al. Differential accumulation of proteoglycans and hyaluronan in culprit lesions: insights into plaque erosion. Arterioscler Thromb Vasc Biol 2002;22:1642-8.

41. Franck G, Mawson T, Sausen G, et al. Flow Perturbation Mediates Neutrophil Recruitment and Potentiates Endothelial Injury via TLR2 in Mice: Implications for Superficial Erosion. Circ Res 2017;121:31-42.

42. Quillard T, Araujo HA, Franck G, et al. TLR2 and neutrophils potentiate endothelial stress, apoptosis and detachment: implications for superficial erosion. Eur Heart J 2015;36:1394-404.

43. Muller JE, Tofler GH, Stone PH. Circadian variation and triggers of onset of acute cardiovascular disease. Circulation 1989;79:733-43.

44. Lee RT, Libby P. The unstable atheroma. Arterioscler Thromb Vasc Biol 1997;17:1859-67.

45. Kolodgie FD, Burke AP, Farb A, et al. The thin-cap fibroatheroma: a type of vulnerable plaque: the major precursor lesion to acute coronary syndromes. Curr Opin Cardiol 2001;16:285-92.

46. Ambrose JA, Tannenbaum MA, Alexopoulos D, et al. Angiographic progression of coronary artery disease and the development of myocardial infarction. J Am Coll Cardiol 1988;12:56-62.

47. Glaser R, Selzer F, Faxon DP, et al. Clinical progression of incidental, asymptomatic lesions discovered during culprit vessel coronary intervention. Circulation 2005;111:143-9.

48. Anderson JL, Adams CD, Antman EM, et al. ACC/AHA 2007 guidelines for the management of patients with unstable angina/non-ST-Elevation myocardial infarction: a report of the American College of Cardiology/American Heart Association Task Force on Practice Guidelines (Writing Committee to Revise the 2002 Guidelines for the Management of Patients With Unstable Angina/ Non-ST-Elevation Myocardial Infarction) developed in collaboration with the American College of Emergency Physicians, the Society for Cardiovascular Angiography and Interventions, and the Society of Thoracic Surgeons endorsed by the American Association of Cardiovascular and Pulmonary Rehabilitation and the Society for Academic Emergency Medicine. J Am Coll Cardiol 2007;50:e1-e157.

49. Kushner FG, Hand M, Smith SC Jr, et al. 2009 Focused Updates: ACC/AHA Guidelines for the Management of Patients With ST-Elevation Myocardial Infarction (updating the 2004 Guideline and 2007 Focused Update) and ACC/AHA/SCAI Guidelines on Percutaneous Coronary Intervention (updating the 2005 Guideline and 2007 Focused Update): a report of the American College of Cardiology Foundation/American Heart Association Task Force on Practice Guidelines. Circulation 2009;120:2271-306.

50. Cannon CP, Braunwald E, McCabe CH, et al. Intensive versus moderate lipid lowering with statins after acute coronary syndromes. N Engl J Med 2004;350:1495-504.

51. Stone GW, Maehara A, Lansky AJ, et al. A prospective natural-history study of coronary atherosclerosis. N Engl J Med 2011;364:226-35.

52. Calvert PA, Obaid DR, O'Sullivan M, et al. Association between IVUS findings and adverse outcomes in patients with coronary artery disease: the VIVA (VH-IVUS in Vulnerable Atherosclerosis) Study. JACC Cardiovasc Imaging 2011;4:894-901.

53. Cheng JM, Garcia-Garcia HM, de Boer SP, et al. In vivo detection of high-risk coronary plaques by radiofrequency intravascular ultrasound and cardiovascular outcome: results of the ATHEROREMO-IVUS study. Eur Heart J 2014;35:639-47.

54. Stone PH, Saito S, Takahashi S, et al. Prediction of progression of coronary artery disease and clinical outcomes using vascular profiling of endothelial shear stress and arterial plaque characteristics: the PREDICTION Study. Circulation 2012;126:172-81. 55. Mancini GBJ, Hartigan PM, Shaw LJ, et al. Predicting 
outcome in the COURAGE trial (Clinical Outcomes Utilizing Revascularization and Aggressive Drug Evaluation): coronary anatomy versus ischemia. JACC Cardiovasc Interv 2014;7:195-201.

56. Prati F, Romagnoli E, Gatto L, et al. Relationship between coronary plaque morphology of the left anterior descending artery and 12 months clinical outcome: the CLIMA study. Eur Heart J 2020;41:383-91.

57. Oemrawsingh RM, Cheng JM, Garcia-Garcia HM, et al. Near-infrared spectroscopy predicts cardiovascular outcome in patients with coronary artery disease. J Am Coll Cardiol 2014;64:2510-8.

58. Wu X, Mintz GS, Xu K, et al. The relationship between attenuated plaque identified by intravascular ultrasound and no-reflow after stenting in acute myocardial infarction: the HORIZONS-AMI (Harmonizing Outcomes With Revascularization and Stents in Acute Myocardial Infarction) trial. JACC Cardiovasc Interv 2011;4:495-502.

59. Lee T, Kakuta T, Yonetsu T, et al. Assessment of echoattenuated plaque by optical coherence tomography and its impact on post-procedural creatine kinase-myocardial band elevation in elective stent implantation. JACC Cardiovasc Interv 2011;4:483-91.

60. Yamagishi M, Terashima M, Awano K, et al. Morphology of vulnerable coronary plaque: insights from followup of patients examined by intravascular ultrasound before an acute coronary syndrome. J Am Coll Cardiol 2000;35:106-11.

61. $\mathrm{Pu}$ J, Mintz GS, Brilakis ES, et al. In vivo characterization of coronary plaques: novel findings from comparing greyscale and virtual histology intravascular ultrasound and near-infrared spectroscopy. Eur Heart J. 2012;33:372-83.

62. Pu J, Mintz GS, Biro S, et al. Insights into echo-attenuated plaques, echolucent plaques, and plaques with spotty calcification: novel findings from comparisons among intravascular ultrasound, near-infrared spectroscopy, and pathological histology in 2,294 human coronary artery segments. J Am Coll Cardiol 2014;63:2220-33.

63. Jang IK, Tearney GJ, MacNeill B, et al. In vivo characterization of coronary atherosclerotic plaque by use of optical coherence tomography. Circulation 2005;111:1551-5.

64. Kubo T, Imanishi T, Takarada S, et al. Assessment of culprit lesion morphology in acute myocardial infarction: ability of optical coherence tomography compared with intravascular ultrasound and coronary angioscopy. J Am Coll Cardiol 2007;50:933-9.
65. Xing L, Higuma T, Wang Z, et al. Clinical Significance of Lipid-Rich Plaque Detected by Optical Coherence Tomography: A 4-Year Follow-Up Study. J Am Coll Cardiol 2017;69:2502-13.

66. Di Vito L, Agozzino M, Marco V, et al. Identification and quantification of macrophage presence in coronary atherosclerotic plaques by optical coherence tomography. Eur Heart J Cardiovasc Imaging 2015;16:807-13.

67. Psaltis PJ, Nicholls SJ. Imaging: Focusing light on the vulnerable plaque. Nat Rev Cardiol 2016;13:253-5.

68. Gerbaud E, Weisz G, Tanaka A, et al. Plaque burden can be assessed using intravascular optical coherence tomography and a dedicated automated processing algorithm: a comparison study with intravascular ultrasound. Eur Heart J Cardiovasc Imaging 2020;21:640-52.

69. Campbell KA, Lipinski MJ, Doran AC, et al. Lymphocytes and the adventitial immune response in atherosclerosis. Circ Res 2012;110:889-900.

70. Mulligan-Kehoe MJ, Simons M. Vasa vasorum in normal and diseased arteries. Circulation 2014;129:2557-66.

71. Kolodgie FD, Gold HK, Burke AP, et al. Intraplaque hemorrhage and progression of coronary atheroma. $\mathrm{N}$ Engl J Med 2003;349:2316-25.

72. Taruya A, Tanaka A, Nishiguchi T, et al. Vasa Vasorum Restructuring in Human Atherosclerotic Plaque Vulnerability: A Clinical Optical Coherence Tomography Study. J Am Coll Cardiol 2015;65:2469-77.

73. Abela GS, Kalavakunta JK, Janoudi A, et al. Frequency of Cholesterol Crystals in Culprit Coronary Artery Aspirate During Acute Myocardial Infarction and Their Relation to Inflammation and Myocardial Injury. Am J Cardiol 2017;120:1699-707.

74. Tearney GJ, Regar E, Akasaka T, et al. Consensus standards for acquisition, measurement, and reporting of intravascular optical coherence tomography studies: a report from the International Working Group for Intravascular Optical Coherence Tomography Standardization and Validation. J Am Coll Cardiol 2012;59:1058-72.

75. Gardner CM, Tan H, Hull EL, et al. Detection of lipid core coronary plaques in autopsy specimens with a novel catheter-based near-infrared spectroscopy system. JACC Cardiovasc Imaging 2008;1:638-48.

76. Goldstein JA, Maini B, Dixon SR, et al. Detection of lipidcore plaques by intracoronary near-infrared spectroscopy identifies high risk of periprocedural myocardial infarction. Circ Cardiovasc Interv 2011;4:429-37.

77. Madder RD, Smith JL, Dixon SR, et al. Composition of 
target lesions by near-infrared spectroscopy in patients with acute coronary syndrome versus stable angina. Circ Cardiovasc Interv 2012;5:55-61.

78. Madder RD, Husaini M, Davis AT, et al. Detection by near-infrared spectroscopy of large lipid cores at culprit sites in patients with non-ST-segment elevation myocardial infarction and unstable angina. Catheter Cardiovasc Interv 2015;86:1014-21.

79. Madder RD, Goldstein JA, Madden SP, et al. Detection by near-infrared spectroscopy of large lipid core plaques at culprit sites in patients with acute ST-segment elevation myocardial infarction. JACC Cardiovasc Interv 2013;6:838-46.

80. Karlsson S, Anesater E, Fransson K, et al. Intracoronary near-infrared spectroscopy and the risk of future cardiovascular events. Open Heart 2019;6:e000917.

81. Danek BA, Karatasakis A, Karacsonyi J, et al. Longterm follow-up after near-infrared spectroscopy coronary imaging: Insights from the lipid cORe plaque association with CLinical events (ORACLE-NIRS) registry. Cardiovasc Revasc Med 2017;18:177-81.

82. Madder RD, Husaini M, Davis AT, et al. Large lipid-rich coronary plaques detected by near-infrared spectroscopy at non-stented sites in the target artery identify patients likely to experience future major adverse cardiovascular events. Eur Heart J Cardiovasc Imaging 2016;17:393-9.

83. Waksman R, Torguson R, Spad MA, et al. The Lipid-Rich Plaque Study of vulnerable plaques and vulnerable patients: Study design and rationale. Am Heart J 2017;192:98-104.

84. Jia H, Abtahian F, Aguirre AD, et al. In vivo diagnosis of plaque erosion and calcified nodule in patients with acute coronary syndrome by intravascular optical coherence tomography. J Am Coll Cardiol 2013;62:1748-58.

85. Nishimiya K, Yin B, Piao Z, et al. Micro-Optical Coherence Tomography for Endothelial Cell Visualization in the Coronary Arteries. JACC Cardiovasc Imaging 2019;12:1878-80.

86. Vanzetto G, Berger-Coz E, Barone-Rochette G, et al. Prevalence, therapeutic management and medium-term prognosis of spontaneous coronary artery dissection: results from a database of 11,605 patients. Eur J Cardiothorac Surg 2009;35:250-4.

87. Thayer JO, Healy RW, Maggs PR. Spontaneous coronary artery dissection. Ann Thorac Surg 1987;44:97-102.

88. Aoki T, Rodriguez-Porcel M, Matsuo Y, et al. Evaluation of coronary adventitial vasa vasorum using $3 \mathrm{D}$ optical coherence tomography--animal and human studies. Atherosclerosis 2015;239:203-8.
89. Kwon TG, Gulati R, Matsuzawa Y, et al. Proliferation of Coronary Adventitial Vasa Vasorum in Patients With Spontaneous Coronary Artery Dissection. JACC Cardiovasc Imaging 2016;9:891-2.

90. Nissen SE, Tuzcu EM, Schoenhagen P, et al. Effect of intensive compared with moderate lipid-lowering therapy on progression of coronary atherosclerosis: a randomized controlled trial. JAMA 2004;291:1071-80.

91. Nissen SE, Nicholls SJ, Sipahi I, et al. Effect of very high-intensity statin therapy on regression of coronary atherosclerosis: the ASTEROID trial. JAMA 2006;295:1556-65.

92. Nicholls SJ, Ballantyne CM, Barter PJ, et al. Effect of two intensive statin regimens on progression of coronary disease. N Engl J Med 2011;365:2078-87.

93. Komukai K, Kubo T, Kitabata H, et al. Effect of atorvastatin therapy on fibrous cap thickness in coronary atherosclerotic plaque as assessed by optical coherence tomography: the EASY-FIT study. J Am Coll Cardiol 2014;64:2207-17.

94. Kini AS, Baber U, Kovacic JC, et al. Changes in plaque lipid content after short-term intensive versus standard statin therapy: the YELLOW trial (reduction in yellow plaque by aggressive lipid-lowering therapy). J Am Coll Cardiol 2013;62:21-9.

95. Kovarnik T, Mintz GS, Skalicka H, et al. Virtual histology evaluation of atherosclerosis regression during atorvastatin and ezetimibe administration: HEAVEN study. Circ J 2012;76:176-83.

96. Nicholls SJ, Puri R, Anderson T, et al. Effect of Evolocumab on Progression of Coronary Disease in Statin-Treated Patients: The GLAGOV Randomized Clinical Trial. JAMA 2016;316:2373-84.

97. Nicholls SJ, Puri R, Anderson T, et al. Effect of Evolocumab on Coronary Plaque Composition. J Am Coll Cardiol 2018;72:2012-21.

98. Nissen SE, Tsunoda T, Tuzcu EM, et al. Effect of recombinant ApoA-I Milano on coronary atherosclerosis in patients with acute coronary syndromes: a randomized controlled trial. JAMA 2003;290:2292-300.

99. Tardif JC, Gregoire J, L'Allier PL, et al. Effects of reconstituted high-density lipoprotein infusions on coronary atherosclerosis: a randomized controlled trial. JAMA 2007;297:1675-82.

100.Tardif JC, Ballantyne CM, Barter P, et al. Effects of the high-density lipoprotein mimetic agent CER001 on coronary atherosclerosis in patients with acute coronary syndromes: a randomized trial. Eur Heart J 
2014;35:3277-86.

101. Andrews J, Janssan A, Nguyen T, et al. Effect of serial infusions of reconstituted high-density lipoprotein (CER001) on coronary atherosclerosis: rationale and design of the CARAT study. Cardiovasc Diagn Ther 2017;7:45-51.

102. Nicholls SJ, Tuzcu EM, Brennan DM, et al. Cholesteryl ester transfer protein inhibition, high-density lipoprotein raising, and progression of coronary atherosclerosis: insights from ILLUSTRATE (Investigation of Lipid Level Management Using Coronary Ultrasound to Assess Reduction of Atherosclerosis by CETP Inhibition and HDL Elevation). Circulation 2008;118:2506-14.

103. Nissen SE, Nicholls SJ, Wolski K, et al. Comparison of pioglitazone vs glimepiride on progression of coronary atherosclerosis in patients with type 2 diabetes: the PERISCOPE randomized controlled trial. JAMA 2008;299:1561-73.

104. Nissen SE, Tuzcu EM, Libby P, et al. Effect of antihypertensive agents on cardiovascular events in patients with coronary disease and normal blood pressure: the CAMELOT study: a randomized controlled trial. JAMA 2004;292:2217-25.

105. Nicholls SJ, Bakris GL, Kastelein JJ, et al. Effect of aliskiren on progression of coronary disease in patients with prehypertension: the AQUARIUS randomized clinical trial. JAMA 2013;310:1135-44.

106. Baigent C, Keech A, Kearney PM, et al. Efficacy and safety of cholesterol-lowering treatment: prospective metaanalysis of data from 90,056 participants in 14 randomised trials of statins. Lancet 2005;366:1267-78.

107. Nissen SE, Tuzcu EM, Schoenhagen P, et al. Statin therapy, LDL cholesterol, C-reactive protein, and coronary artery disease. N Engl J Med 2005;352:29-38.

108. Puri R, Nissen SE, Shao M, et al. Impact of baseline lipoprotein and C-reactive protein levels on coronary atheroma regression following high-intensity statin therapy. Am J Cardiol 2014;114:1465-72.

109.Puri R, Nicholls SJ, Shao M, et al. Impact of statins on serial coronary calcification during atheroma progression and regression. J Am Coll Cardiol 2015;65:1273-82.

110.Habara M, Nasu K, Terashima M, et al. Impact on optical coherence tomographic coronary findings of fluvastatin alone versus fluvastatin + ezetimibe. Am J Cardiol 2014;113:580-7.

111.Kini AS, Vengrenyuk Y, Shameer K, et al. Intracoronary Imaging, Cholesterol Efflux, and Transcriptomes After Intensive Statin Treatment: The YELLOW II Study. J Am Coll Cardiol 2017;69:628-40.
112. Abifadel M, Varret M, Rabes JP, et al. Mutations in PCSK9 cause autosomal dominant hypercholesterolemia. Nat Genet 2003;34:154-6.

113. Maxwell KN, Breslow JL. Adenoviral-mediated expression of Pcsk9 in mice results in a low-density lipoprotein receptor knockout phenotype. Proc Natl Acad Sci U S A 2004;101:7100-5.

114. Seidah NG, Benjannet S, Wickham L, et al. The secretory proprotein convertase neural apoptosis-regulated convertase 1 (NARC-1): liver regeneration and neuronal differentiation. Proc Natl Acad Sci U S A 2003;100:928-33.

115. Blom DJ, Hala T, Bolognese M, et al. A 52-week placebocontrolled trial of evolocumab in hyperlipidemia. N Engl J Med 2014;370:1809-19.

116. Gordon T, Castelli WP, Hjortland MC, et al. High density lipoprotein as a protective factor against coronary heart disease. The Framingham Study. Am J Med 1977;62:707-14.

117. Barter P, Gotto AM, LaRosa JC, et al. HDL cholesterol, very low levels of LDL cholesterol, and cardiovascular events. N Engl J Med 2007;357:1301-10.

118. Rye KA, Barter PJ. Formation and metabolism of prebetamigrating, lipid-poor apolipoprotein A-I. Arterioscler Thromb Vasc Biol 2004;24:421-8.

119. Bisoendial RJ, Hovingh GK, Levels JH, et al. Restoration of endothelial function by increasing high-density lipoprotein in subjects with isolated low high-density lipoprotein. Circulation 2003;107:2944-8.

120.Lee K, Ahn TH, Kang WC, et al. The effects of statin and niacin on plaque stability, plaque regression, inflammation and oxidative stress in patients with mild to moderate coronary artery stenosis. Korean Circ J 2011;41:641-8.

121.HPS2-THRIVE Collaborative Group, Landray MJ, Haynes R, et al. Effects of extended-release niacin with laropiprant in high-risk patients. N Engl J Med 2014;371:203-12.

122. Nicholls SJ, Tuzcu EM, Sipahi I, et al. Relationship between atheroma regression and change in lumen size after infusion of apolipoprotein A-I Milano. J Am Coll Cardiol 2006;47:992-7.

123. Waksman R, Torguson R, Kent KM, et al. A first-inman, randomized, placebo-controlled study to evaluate the safety and feasibility of autologous delipidated highdensity lipoprotein plasma infusions in patients with acute coronary syndrome. J Am Coll Cardiol 2010;55:2727-35.

124. Barter PJ, Brewer HB Jr, Chapman MJ, et al. Cholesteryl ester transfer protein: a novel target for raising HDL and inhibiting atherosclerosis. Arterioscler Thromb Vasc Biol 
2003;23:160-7.

125. Boekholdt SM, Kuivenhoven JA, Wareham NJ, et al. Plasma levels of cholesteryl ester transfer protein and the risk of future coronary artery disease in apparently healthy men and women: the prospective EPIC (European Prospective Investigation into Cancer and nutrition)Norfolk population study. Circulation 2004;110:1418-23.

126. Nissen SE, Tardif JC, Nicholls SJ, et al. Effect of torcetrapib on the progression of coronary atherosclerosis. N Engl J Med 2007;356:1304-16.

127. Vergeer M, Stroes ES. The pharmacology and off-target effects of some cholesterol ester transfer protein inhibitors. Am J Cardiol 2009;104:32E-8E.

128. Bailey D, Jahagirdar R, Gordon A, et al. RVX-208: a small molecule that increases apolipoprotein A-I and highdensity lipoprotein cholesterol in vitro and in vivo. J Am Coll Cardiol 2010;55:2580-9.

129. Quispe R, Manalac RJ, Faridi KF, et al. Relationship of the triglyceride to high-density lipoprotein cholesterol (TG/HDL-C) ratio to the remainder of the lipid profile: The Very Large Database of Lipids-4 (VLDL-4) study. Atherosclerosis 2015;242:243-50.

130. Miller M, Cannon CP, Murphy SA, et al. Impact of triglyceride levels beyond low-density lipoprotein cholesterol after acute coronary syndrome in the PROVE IT-TIMI 22 trial. J Am Coll Cardiol 2008;51:724-30.

131. Murray CJ, Lopez AD. Alternative projections of mortality and disability by cause 1990-2020: Global Burden of Disease Study. Lancet 1997;349:1498-504.

132. Huxley R, Barzi F, Woodward M. Excess risk of fatal coronary heart disease associated with diabetes in men and women: meta-analysis of 37 prospective cohort studies. BMJ 2006;332:73-8.

133. Donnan PT, Boyle DI, Broomhall J, et al. Prognosis following first acute myocardial infarction in Type 2 diabetes: a comparative population study. Diabet Med 2002;19:448-55.

134. Flaherty JD, Davidson CJ. Diabetes and coronary revascularization. JAMA. 2005;293:1501-8.

135.Nicholls SJ, Tuzcu EM, Kalidindi S, et al. Effect of diabetes on progression of coronary atherosclerosis and arterial remodeling: a pooled analysis of 5 intravascular ultrasound trials. J Am Coll Cardiol 2008;52:255-62.

136. Stegman B, Puri R, Cho L, et al. High-intensity statin therapy alters the natural history of diabetic coronary atherosclerosis: insights from SATURN. Diabetes Care 2014;37:3114-20.

137. Nicholls SJ, Tuzcu EM, Wolski K, et al. Lowering the triglyceride/high-density lipoprotein cholesterol ratio is associated with the beneficial impact of pioglitazone on progression of coronary atherosclerosis in diabetic patients: insights from the PERISCOPE (Pioglitazone Effect on Regression of Intravascular Sonographic Coronary Obstruction Prospective Evaluation) study. J Am Coll Cardiol 2011;57:153-9.

138.Zinman B, Wanner C, Lachin JM, et al. Empagliflozin, Cardiovascular Outcomes, and Mortality in Type 2 Diabetes. N Engl J Med 2015;373:2117-28.

139. Neal B, Perkovic V, Mahaffey KW, et al. Canagliflozin and Cardiovascular and Renal Events in Type 2 Diabetes. N Engl J Med 2017;377:644-57.

140.Wiviott SD, Raz I, Bonaca MP, et al. Dapagliflozin and Cardiovascular Outcomes in Type 2 Diabetes. N Engl J Med 2019;380:347-57.

141. Marso SP, Daniels GH, Brown-Frandsen K, et al. Liraglutide and Cardiovascular Outcomes in Type 2 Diabetes. N Engl J Med 2016;375:311-22.

142.Marso SP, Bain SC, Consoli A, et al. Semaglutide and Cardiovascular Outcomes in Patients with Type 2 Diabetes. N Engl J Med 2016;375:1834-44.

143. Gerstein HC, Colhoun HM, Dagenais GR, et al. Dulaglutide and cardiovascular outcomes in type 2 diabetes (REWIND): a double-blind, randomised placebocontrolled trial. Lancet 2019;394:121-30.

144.Kataoka Y, Shao M, Wolski K, et al. Multiple risk factor intervention and progression of coronary atherosclerosis in patients with type 2 diabetes mellitus. Eur J Prev Cardiol 2013;20:209-17.

145. Blood Pressure Lowering Treatment Trialists' Collaboration. Blood pressure-lowering treatment based on cardiovascular risk: a meta-analysis of individual patient data. Lancet 2014;384:591-8.

146. Sipahi I, Tuzcu EM, Schoenhagen P, et al. Effects of normal, pre-hypertensive, and hypertensive blood pressure levels on progression of coronary atherosclerosis. J Am Coll Cardiol 2006;48:833-8.

147. Ferrario CM, Strawn WB. Role of the renin-angiotensinaldosterone system and proinflammatory mediators in cardiovascular disease. Am J Cardiol 2006;98:121-8.

148. Heart Outcomes Prevention Evaluation Study Investigators, Yusuf S, Sleight P, et al. Effects of an angiotensin-converting-enzyme inhibitor, ramipril, on cardiovascular events in high-risk patients. N Engl J Med 2000;342:145-53.

149. Madssen E, Moholdt T, Videm V, et al. Coronary atheroma regression and plaque characteristics assessed by 
grayscale and radiofrequency intravascular ultrasound after aerobic exercise. Am J Cardiol 2014;114:1504-11.

150. Nguyen MT, Fernando S, Schwarz N, et al. Inflammation as a Therapeutic Target in Atherosclerosis. J Clin Med 2019. doi: 10.3390/jcm8081109.

151. Ridker PM, Everett BM, Thuren T, et al. Antiinflammatory Therapy with Canakinumab for Atherosclerotic Disease. N Engl J Med 2017;377:1119-31.

152. Ridker PM, Everett BM, Pradhan A, et al. Low-Dose Methotrexate for the Prevention of Atherosclerotic Events. N Engl J Med 2019;380:752-62.

153. Tardif JC, Kouz S, Waters DD, et al. Efficacy and Safety of Low-Dose Colchicine after Myocardial Infarction. N Engl J Med 2019;381:2497-505.

154.Komatsu R, Ueda M, Naruko T, et al. Neointimal tissue response at sites of coronary stenting in humans: macroscopic, histological, and immunohistochemical analyses. Circulation 1998;98:224-33.

155.Dangas GD, Claessen BE, Caixeta A, et al. In-stent restenosis in the drug-eluting stent era. J Am Coll Cardiol. 2010;56:1897-907.

156. Camenzind E, Steg PG, Wijns W. Stent thrombosis late after implantation of first-generation drug-eluting stents: a cause for concern. Circulation 2007;115:1440-55; discussion 1455 .

157. Lagerqvist B, James SK, Stenestrand U, et al. Long-term outcomes with drug-eluting stents versus bare-metal stents in Sweden. N Engl J Med 2007;356:1009-19.

158. Palmerini T, Kirtane AJ, Serruys PW, et al. Stent thrombosis with everolimus-eluting stents: meta-analysis of comparative randomized controlled trials. Circ Cardiovasc Interv 2012;5:357-64.

159. Awata M, Kotani J, Uematsu M, et al. Serial angioscopic evidence of incomplete neointimal coverage after sirolimus-eluting stent implantation: comparison with bare-metal stents. Circulation 2007;116:910-6.

160. Mauri L, Hsieh WH, Massaro JM, et al. Stent thrombosis in randomized clinical trials of drug-eluting stents. N Engl J Med 2007;356:1020-9.

161.Finn AV, Joner M, Nakazawa G, et al. Pathological correlates of late drug-eluting stent thrombosis: strut coverage as a marker of endothelialization. Circulation 2007;115:2435-41.

162.Joner M, Finn AV, Farb A, et al. Pathology of drug-eluting stents in humans: delayed healing and late thrombotic risk. J Am Coll Cardiol 2006;48:193-202.

163. Gutiérrez-Chico JL, Regar E, Nüesch E, et al. Delayed coverage in malapposed and side-branch struts with respect to well-apposed struts in drug-eluting stents: in vivo assessment with optical coherence tomography. Circulation 2011;124:612-23.

164.Park SJ, Kang SJ, Virmani R, et al. In-stent neoatherosclerosis: a final common pathway of late stent failure. J Am Coll Cardiol 2012;59:2051-7.

165. Nakazawa G, Vorpahl M, Finn AV, et al. One step forward and two steps back with drug-eluting-stents: from preventing restenosis to causing late thrombosis and nouveau atherosclerosis. JACC Cardiovasc Imaging 2009;2:625-8.

166. Nakazawa G, Otsuka F, Nakano M, et al. The pathology of neoatherosclerosis in human coronary implants bare-metal and drug-eluting stents. J Am Coll Cardiol 2011;57:1314-22.

167. Guagliumi G, Sirbu V, Musumeci G, et al. Examination of the in vivo mechanisms of late drug-eluting stent thrombosis: findings from optical coherence tomography and intravascular ultrasound imaging. JACC Cardiovasc Interv 2012;5:12-20.

168. Ozaki Y, Okumura M, Ismail TF, et al. The fate of incomplete stent apposition with drug-eluting stents: an optical coherence tomography-based natural history study. Eur Heart J 2010;31:1470-6.

169. Matsumoto D, Shite J, Shinke T, et al. Neointimal coverage of sirolimus-eluting stents at 6-month follow-up: evaluated by optical coherence tomography. Eur Heart J 2007;28:961-7.

170. Guagliumi G, Costa MA, Sirbu V, et al. Strut coverage and late malapposition with paclitaxel-eluting stents compared with bare metal stents in acute myocardial infarction: optical coherence tomography substudy of the Harmonizing Outcomes with Revascularization and Stents in Acute Myocardial Infarction (HORIZONS-AMI) Trial. Circulation 2011;123:274-81.

171. Barlis P, Regar E, Serruys PW, et al. An optical coherence tomography study of a biodegradable vs. durable polymercoated limus-eluting stent: a LEADERS trial sub-study. Eur Heart J 2010;31:165-76.

172. Gutiérrez-Chico JL, Jüni P, García-García HM, et al. Long-term tissue coverage of a biodegradable polylactide polymer-coated biolimus-eluting stent: comparative sequential assessment with optical coherence tomography until complete resorption of the polymer. Am Heart J 2011;162:922-31.

173. Gutiérrez-Chico JL, van Geuns RJ, Regar E, et al. Tissue coverage of a hydrophilic polymer-coated zotarolimuseluting stent vs. a fluoropolymer-coated everolimus- 
eluting stent at 13-month follow-up: an optical coherence tomography substudy from the RESOLUTE All Comers trial. Eur Heart J 2011;32:2454-63.

174. Nakazawa G, Finn AV, Joner M, et al. Delayed arterial healing and increased late stent thrombosis at culprit sites after drug-eluting stent placement for acute myocardial infarction patients: an autopsy study. Circulation 2008;118:1138-45.

175. Gonzalo N, Barlis P, Serruys PW, et al. Incomplete stent apposition and delayed tissue coverage are more frequent in drug-eluting stents implanted during primary percutaneous coronary intervention for ST-segment elevation myocardial infarction than in drug-eluting stents implanted for stable/unstable angina: insights from optical coherence tomography. JACC Cardiovasc Interv 2009;2:445-52.

176. Kubo T, Imanishi T, Kitabata H, et al. Comparison of vascular response after sirolimus-eluting stent implantation between patients with unstable and stable angina pectoris: a serial optical coherence tomography study. JACC Cardiovasc Imaging 2008;1:475-84.

177. Templin C, Meyer M, Muller MF, et al. Coronary optical frequency domain imaging (OFDI) for in vivo evaluation of stent healing: comparison with light and electron microscopy. Eur Heart J 2010;31:1792-801.

178. Nakano M, Vorpahl M, Otsuka F, et al. Ex vivo assessment of vascular response to coronary stents by optical frequency domain imaging. JACC Cardiovasc Imaging 2012;5:71-82.

179.Prati F, Stazi F, Dutary J, et al. Detection of very early

Cite this article as: Montarello NJ, Nelson AJ, Verjans J, Nicholls SJ, Psaltis PJ. The role of intracoronary imaging in translational research. Cardiovasc Diagn Ther 2020;10(5):14801507. doi: $10.21037 / \mathrm{cdt}-20-1$ stent healing after primary angioplasty: an optical coherence tomographic observational study of chromium cobaltum and first-generation drug-eluting stents. The DETECTIVE study. Heart 2011;97:1841-6.

180. Waxman S, Dixon SR, L'Allier P, et al. In vivo validation of a catheter-based near-infrared spectroscopy system for detection of lipid core coronary plaques: initial results of the SPECTACL study. JACC Cardiovasc Imaging 2009;2:858-68.

181. Vranckx P, Valgimigli M, Juni P, et al. Ticagrelor plus aspirin for 1 month, followed by ticagrelor monotherapy for 23 months vs aspirin plus clopidogrel or ticagrelor for 12 months, followed by aspirin monotherapy for 12 months after implantation of a drug-eluting stent: a multicentre, open-label, randomised superiority trial. Lancet 2018;392:940-9.

182. Kedhi E, Latib A, Abizaid A, et al. Rationale and design of the Onyx ONE global randomized trial: A randomized controlled trial of high-bleeding risk patients after stent placement with 1month of dual antiplatelet therapy. Am Heart J 2019;214:134-41.

183.Lee SY, Kim JS, Yoon HJ, et al. Early Strut Coverage in Patients Receiving Drug-Eluting Stents and its Implications for Dual Antiplatelet Therapy: A Randomized Trial. JACC Cardiovasc Imaging 2018;11:1810-9.

184. Worthley SG, Abizaid A, Kirtane AJ, et al. First-inHuman Evaluation of a Novel Polymer-Free Drug-Filled Stent: Angiographic, IVUS, OCT, and Clinical Outcomes From the RevElution Study. JACC Cardiovasc Interv 2017;10:147-56. 